\title{
A 16-beam Non-Scanning Swath Mapping Laser Altimeter Instrument
}

Anthony Yu, Michael Krainak, David Harding, James Abshire, Xiaoli Sun, John Cavanaugh, Susan Valett, Luis Ramos-Izquierdo, Pete Dogoda, Brian Kamamia

\section{Paper 8599-25}

03FEB2012 


\section{Objectives -}

- Develop key technologies to meet the LIST mission requirements and provide scalability study for spaceborne mission.

- Advance TRL of critical subsystems (Laser \& Detector) on airborne platform.

- Develop and demonstrate a $>15 \%$ wall plug efficient laser system coupled with a highly sensitive detector array to realizing the global elevation mapping goals of the LIST mission.

\section{Approaches -}

- Develop and demonstrate a 16-channel airborne instrument - Airborne Lidar Surface Topography Simulator (ALISTS) to demonstrate key subsystems and measurement techniques in support of the LIST mission.

- Key subsystems being matured in this IIP - Laser, Detectors and Optical System.

- COTS - Data Acquisition and Processing Systems

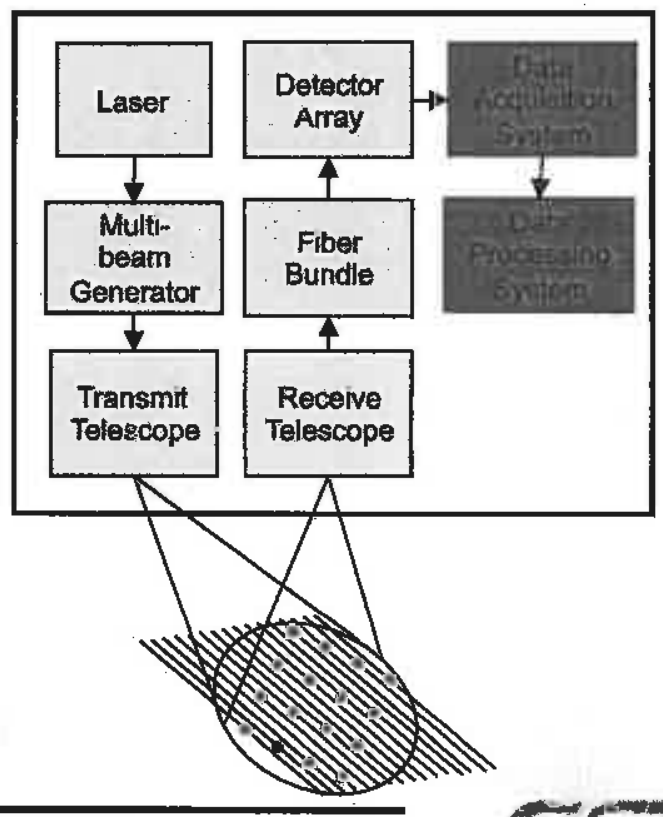


The Lidar Surface Topography mission will serve a diverse array of science and applications objectives, providing foundation dato on the Earth's topography, the height of overlying covers of vegetation, water, snow and ice,
and their change.
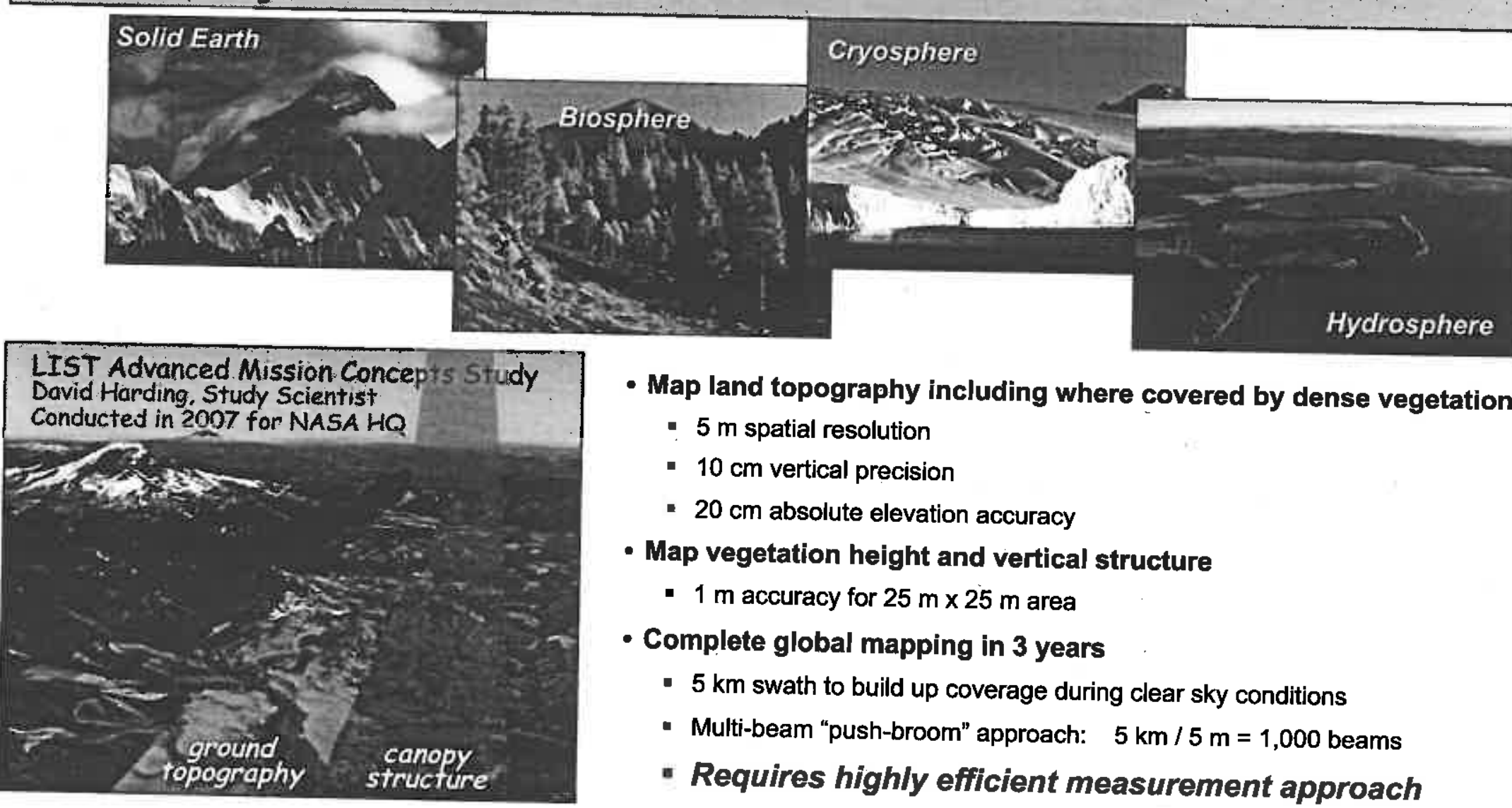

- Map land topography including where covered by dense vegetation

- $5 \mathrm{~m}$ spatial resolution

- $10 \mathrm{~cm}$ vertical precision

- $20 \mathrm{~cm}$ absolute elevation accuracy

- Map vegetation height and vertical structure

- $1 \mathrm{~m}$ accuracy for $25 \mathrm{~m} \times 25 \mathrm{~m}$ area

- Complete global mapping in 3 years

- $5 \mathrm{~km}$ swath to build up coverage during clear sky conditions

- Multi-beam "push-broom" approach: $5 \mathrm{~km} / 5 \mathrm{~m}=1,000$ beams

- Requires highly efficient measurement approach

ALISTS measurement approach developed to meet the demanding LIST requirements 


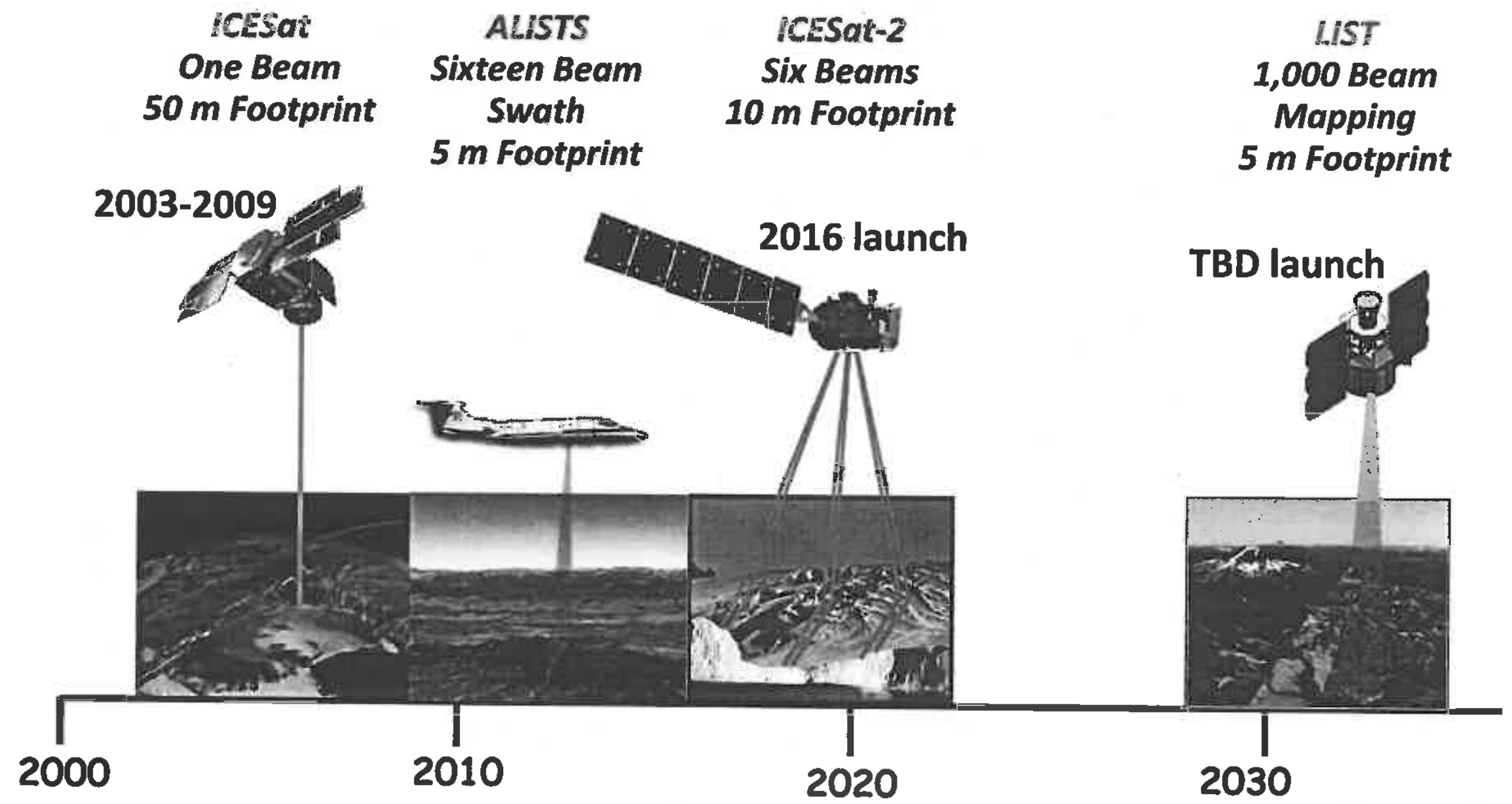




\section{An Efficient Lidar Measurement Approach}

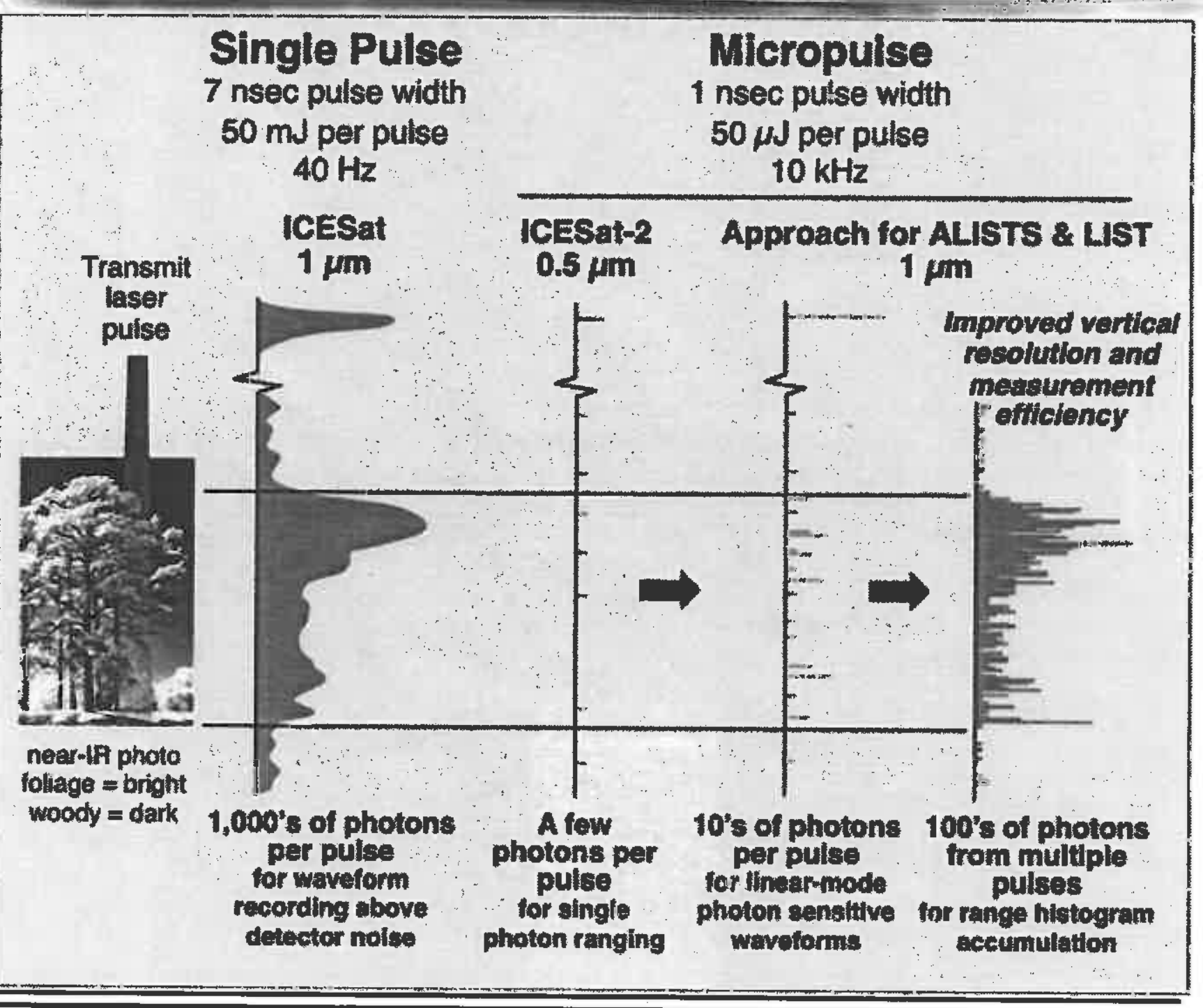

Photonics West 2013 Paper 8599-25

AWY $03 F E B 2012$ 


\section{Key differences between LIST lidar and earlier}

lidars

- Laser Transmitters:

- Low to medium pulse energy and high pulse rate, similar to ICESat-2/ATLAS but at a near IR wavelength

- Much higher electrical to optical conversion efficiency

- Optics and Alignment

- Similar to previous lidars but with up to 1000 instantaneous field of view (IFOV), or pixels, and new challenges in alignment

- Detectors:

- Infrared, single-photon-sensitivity, linear-mode analog output, and multiple element array

- Signal Processing

- On board storage, filtering, and data volume reduction 


\section{NASA IIP ALISTS Instrument Concept \& Performance Prediction}

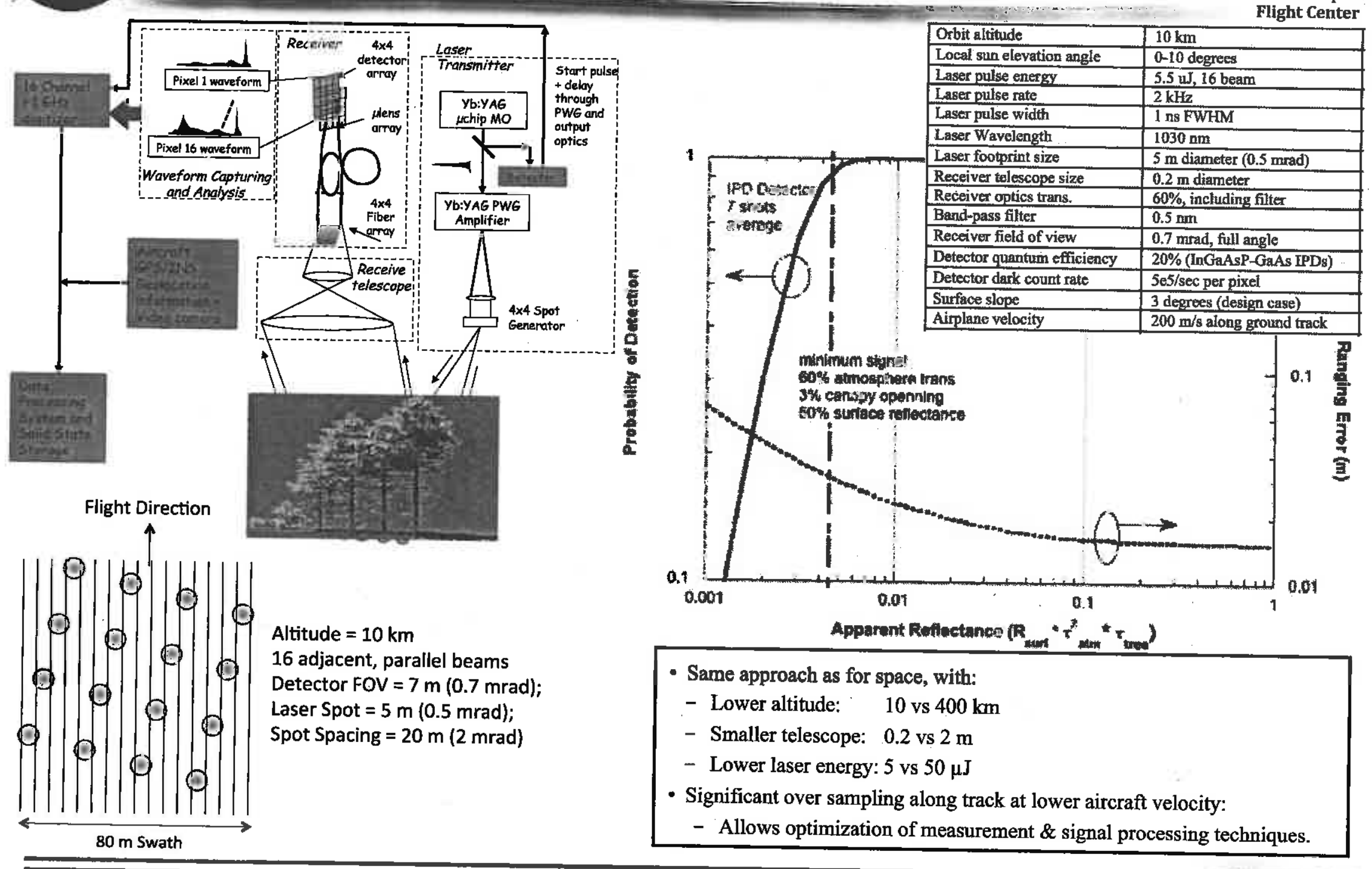


NASA Spaceflight and Airborne Measurement Comparisons \\ All use micropuise fidar with waveform capturing and analysis detection scheme}

\begin{tabular}{|c|c|c|c|}
\hline Parameters & Spaceborne Instrument & $\begin{array}{l}\text { Alrborne Instrument } \\
\text { Engineering Flights }\end{array}$ & $\begin{array}{l}\text { Airborne Instrument } \\
\text { Science Demonstration Flights }\end{array}$ \\
\hline Spatial Resolution & 5 meter & 5 meter & 5 meter \\
\hline Beam Divergence & $12.5 \mu \mathrm{rad}$ & $0.5 \mathrm{mrad}$ & $0.5 \mathrm{mrad}$ \\
\hline Altitude & $400 \mathrm{~km}$ & $32.8 \mathrm{kft} / 10 \mathrm{~km}$ & $-28 \mathrm{kft} / \sim 8 \mathrm{~km}$ \\
\hline Swath Width & $5 \mathrm{~km}$ & $80 \mathrm{~m}$ & $80 \mathrm{~m}$ \\
\hline Laser Energy & $\begin{array}{c}50 \mu \mathrm{J} / \text { beam for } 1000 \text { beams } \\
@ 10 \mathrm{kHz}^{*}\end{array}$ & $\begin{array}{c}\sim 5 \mu \mathrm{J} / \text { beam for } 16 \text { beams } \\
\text { @ } 2 \mathrm{kHz}\end{array}$ & $\begin{array}{c}\sim 5 \mu \mathrm{J} / \text { beam for } 16 \text { beam } \\
@ 10 \mathrm{kHz}\end{array}$ \\
\hline $\begin{array}{l}\text { Detector (> } 1 \mathrm{GHz} \\
\text { bandwidth/pixel) }\end{array}$ & 1000 pixels & 16 pixels & 16 pixels \\
\hline Platform Speed & $7000 \mathrm{~m} / \mathrm{sec}$ & $200 \mathrm{~m}$ isec & $\sim 170 \mathrm{~m} / \mathrm{sec}$ \\
\hline $\begin{array}{l}\text { Number of footprints } \\
\text { per 5-m along track }\end{array}$ & 7 & 50 & 300 \\
\hline
\end{tabular}
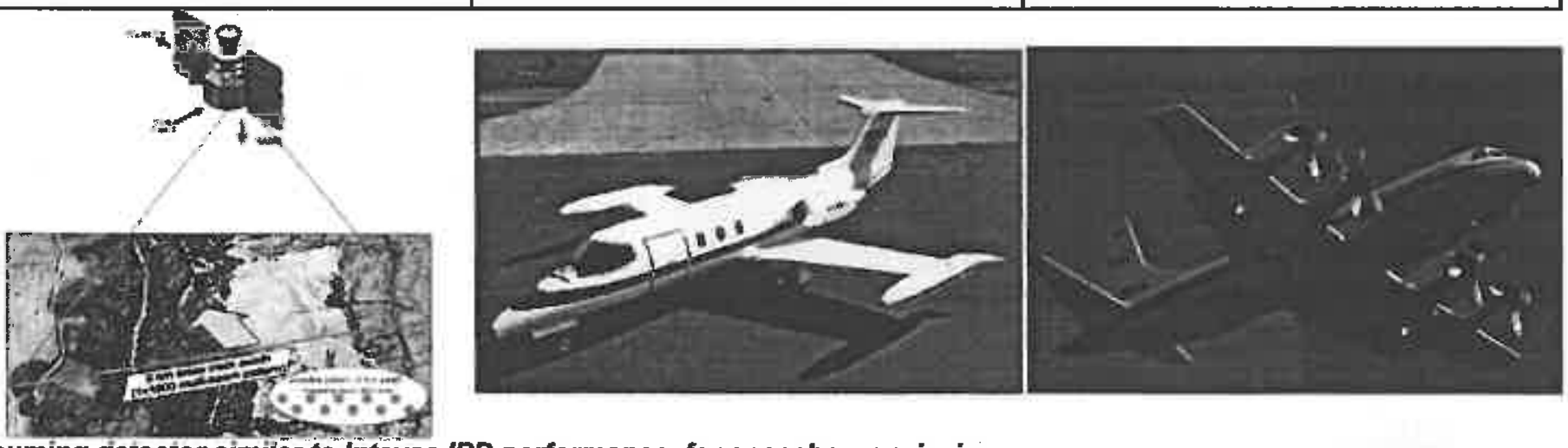

*assuming detector similar to intevac IPD performance for spaceborne mission 


\section{NASA ALISTS Airborne Campaigns}

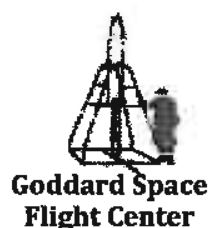

Engineering Flights - Sept 2011

- Platform: Lear-25

- Location: NASA GRC

- Laser: Microchip Laser

- Detector: Intevac 16 element IPD

- Number of beams: 16

- Altitude: $10 \mathrm{~km}$

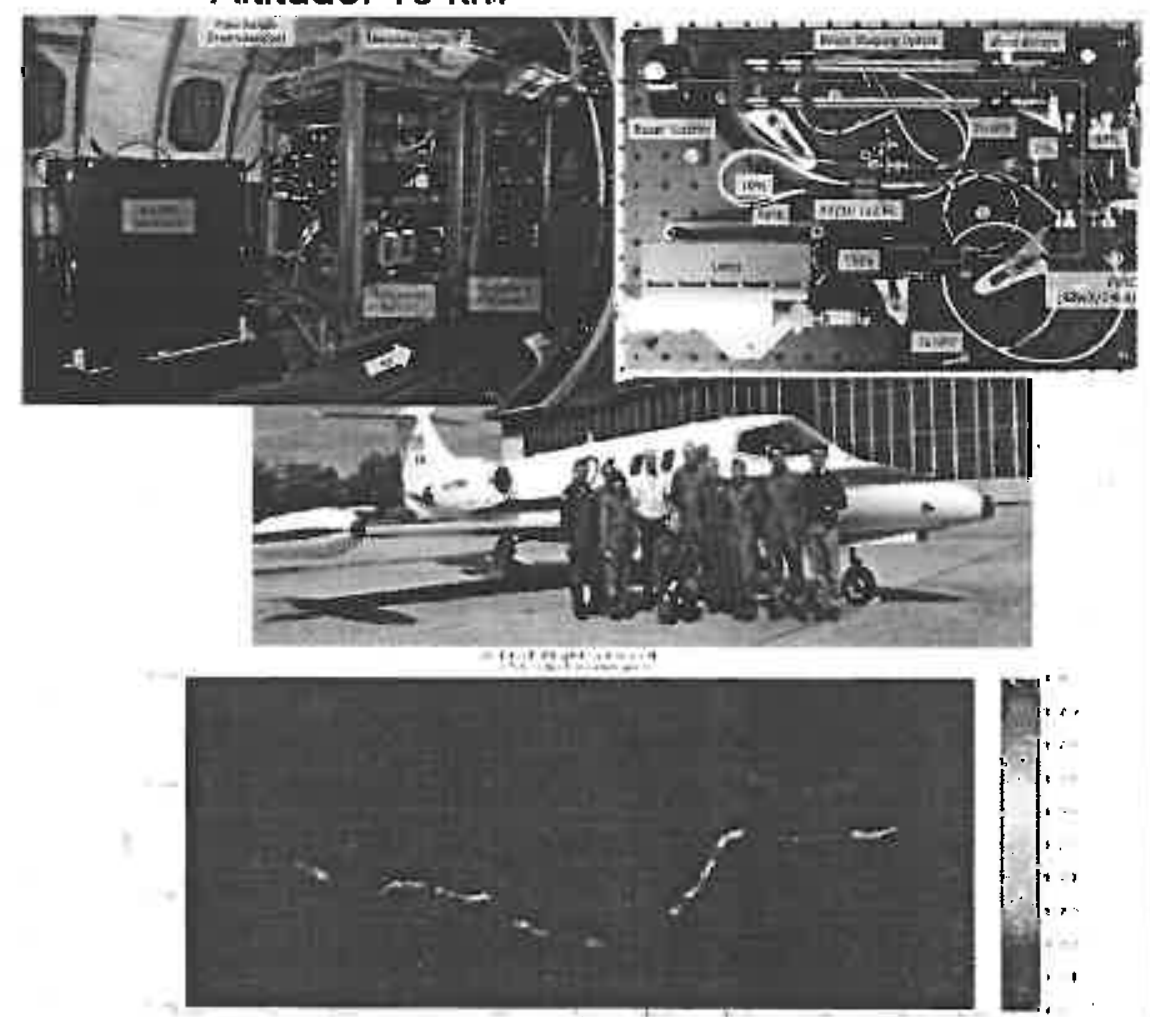

Science Demonstration Flights - Aug 2012

- Platform: P-3B

- Location: NASA WFF

- Laser: Microchip Laser \& MOPA Laser

- Detector: Intevac 16 element IPD

- Number of beams: 16

- Altitude: 1-2 km (due to SNR limitation)
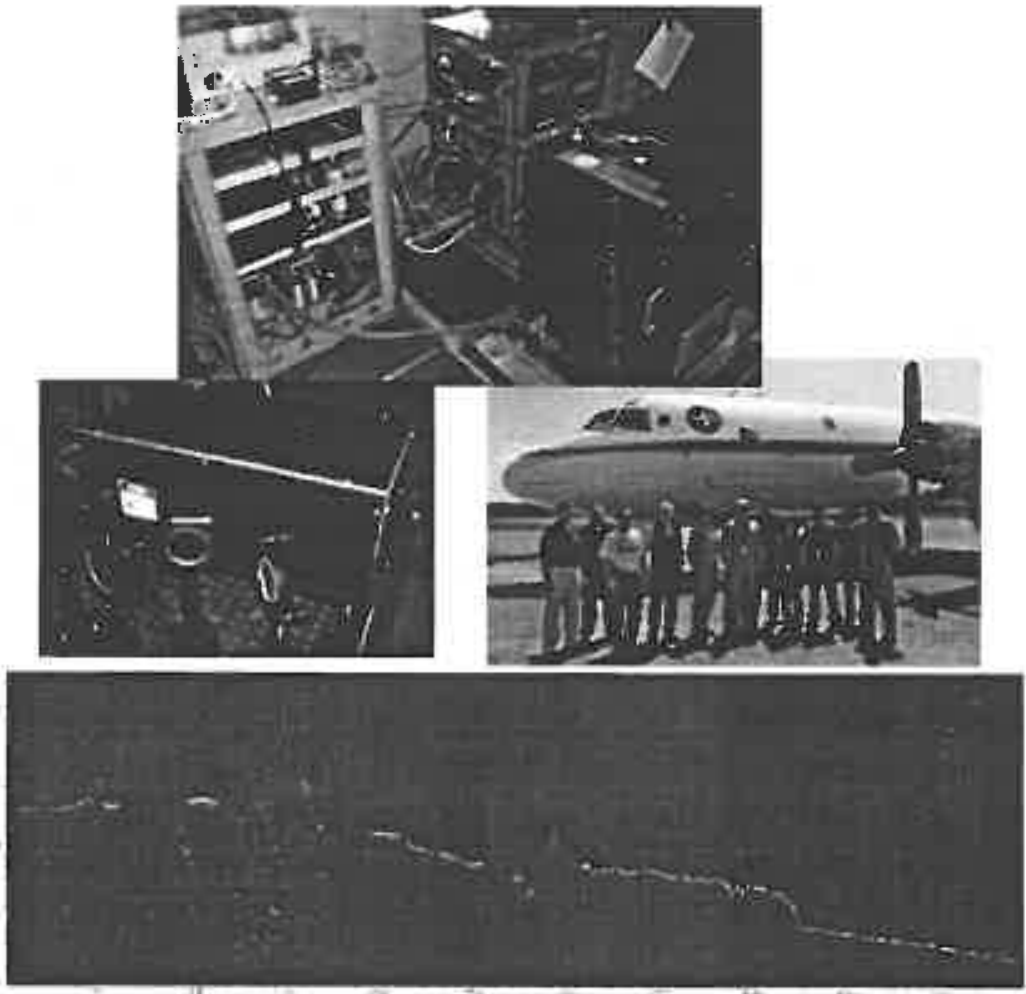

AWY 03FEB2012 


\section{ALISTS Instrument Overview}

\section{JOHN CAVANAUGH}

NASA GSFC CODE 554 
- Measure pulse time of flight

- $0.1 \mathrm{~m}$ accuracy for $1^{\circ}$ slopes

- $0.5 \mathrm{~m}$ accuracy for $10^{\circ}$ slopes

- Signal Characteristics

- $10 \mathrm{kHz}$ pulse repetition rate

- 1 transmit pulse

- 0.7 - 1.0 ns FWHM Gaussian

- 16 received pulses

- Signal spreading < 300 m ( $2 \mu s$ max)

- Detector Bandwidth

- Constant group-delay filter

$-467 \mathrm{MHz}-3 \mathrm{~dB}$

$-1 \mathrm{GHz}-50 \mathrm{~dB}$

- Rx Tracking Requirement

- Track 2 us Rx signal window

- Center sample window on signal

- $\pm 150 \mathrm{~m}$ window

- Adjust at $>2 \mathrm{~Hz}$ rate (5k shots)
- Acquisition Requirements

- 8-bit quantization (ENOB > 6.5)

- Sample rate $>1.5 \mathrm{GS} / \mathrm{s}$

- Data rate for $2 \mu s$ Rx window @ $1.5 \mathrm{GS} / \mathrm{s}$ : 3000 samples $x 16$ channels $R x$ 100 samples $T x$ -> $500 \mathrm{MB} / \mathrm{s}$ continuous rate

- Storage Requirement

- 1 Hour continuous -> 1.8 TB

- Ancillary Data

- Aircraft Nav Data

- GPS \& Attitude (Applanix)

- Nadir video stream 


\section{NASA ALISTS Block Diagram \& Measurement Pattern Goddard Space
Flight Center}
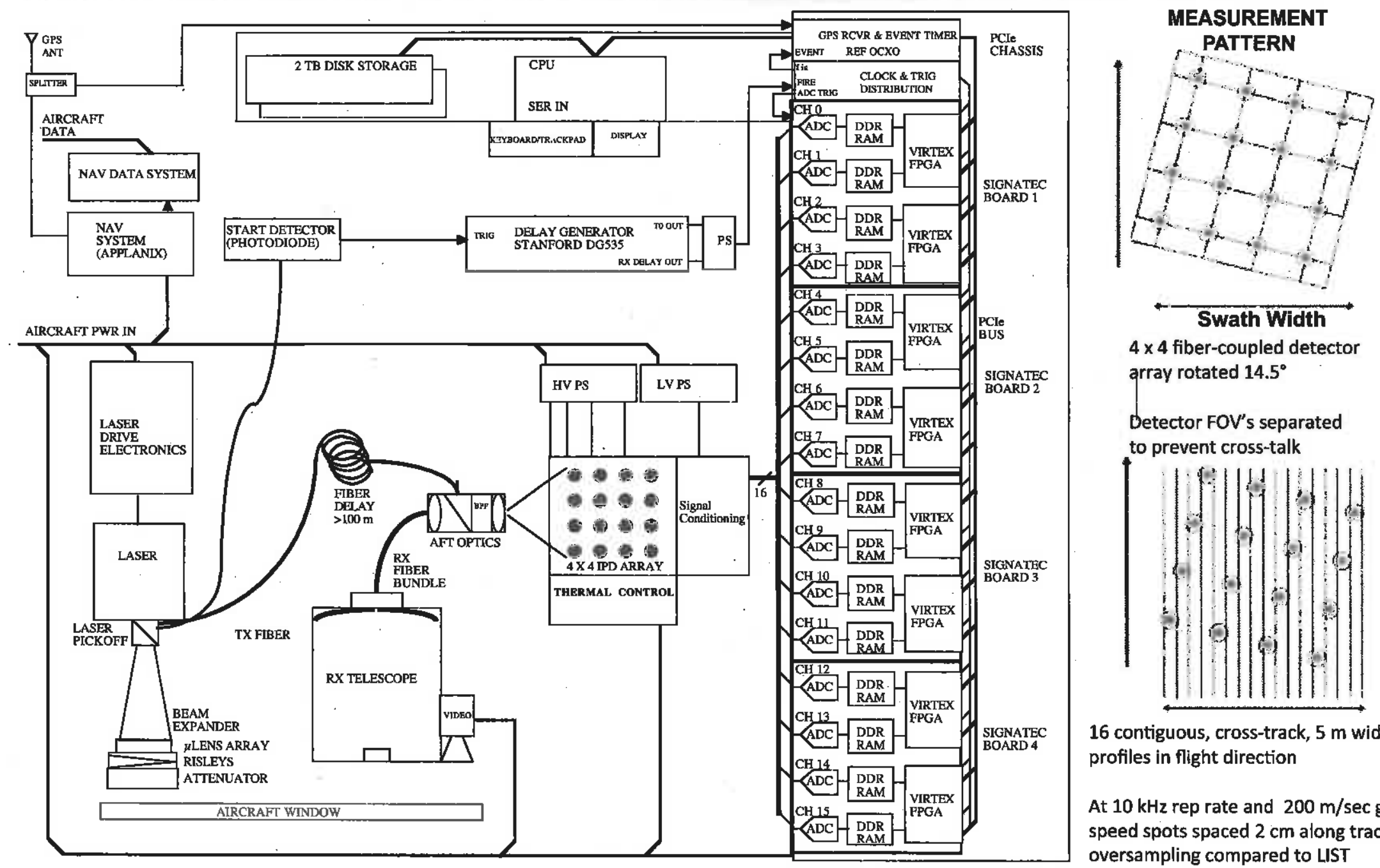

$4 \times 4$ fiber-coupled detector array rotated $14.5^{\circ}$

Detector FOV's separated to prevent cross-talk

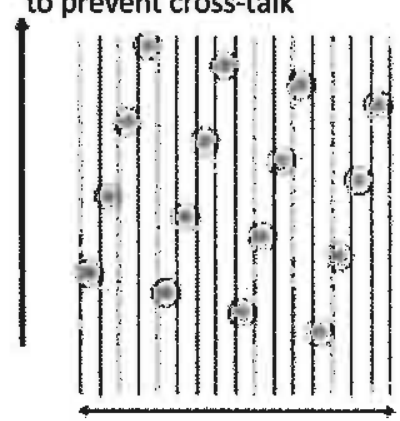

16 contiguous, cross-track, $5 \mathrm{~m}$ wide profiles in flight direction

At $10 \mathrm{kHz}$ rep rate and $200 \mathrm{~m} / \mathrm{sec}$ ground speed spots spaced $2 \mathrm{~cm}$ along track; $35 \mathrm{x}$ oversampling compared to LIST 


\section{ALISTS Transceiver and Racks for Lear-25 and (ans P3 Flight Campaigns}
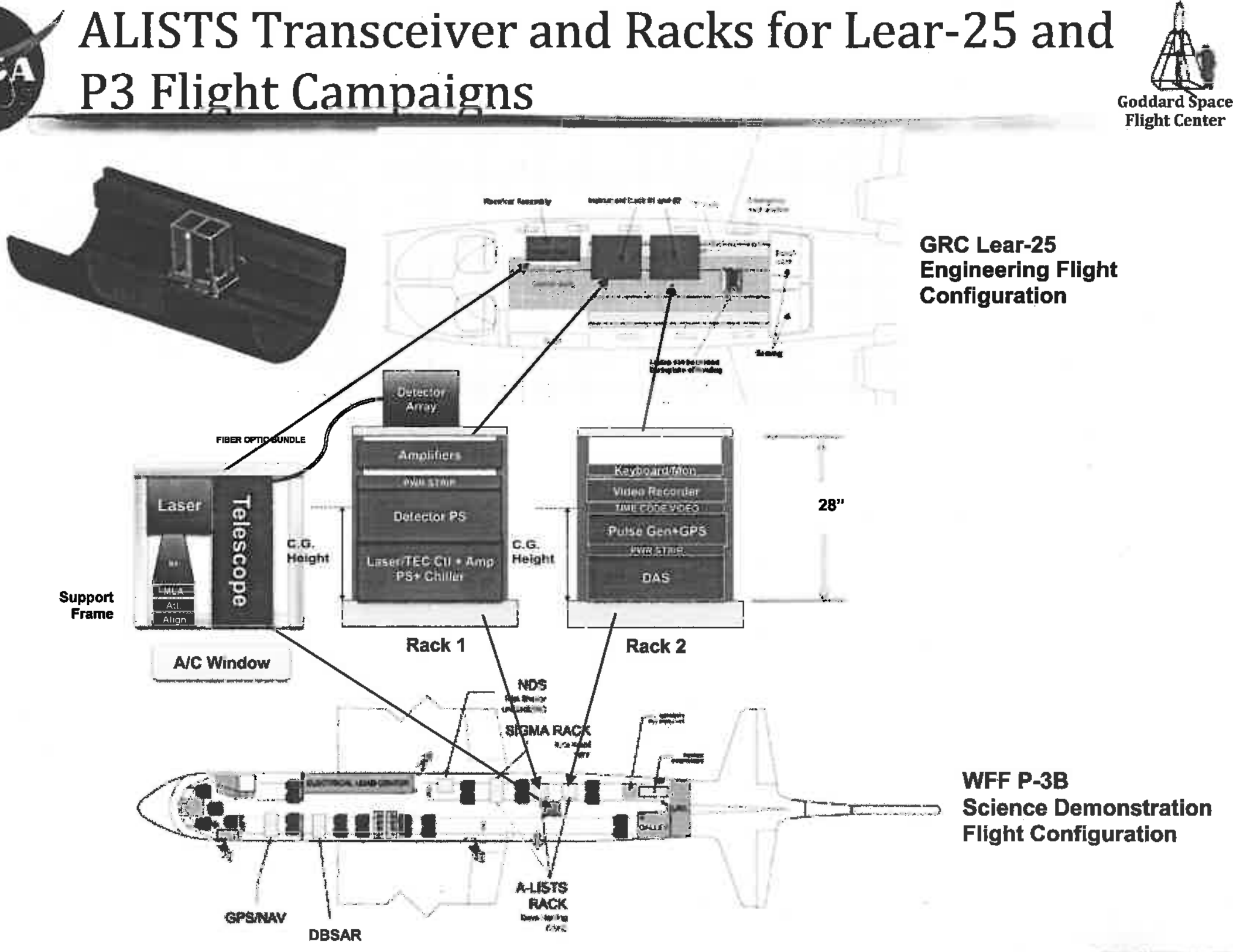

WFF P-3B

Science Demonstration

Flight Configuration 


\section{NASA Yb:YAG Microchip Laser for ALISTS}

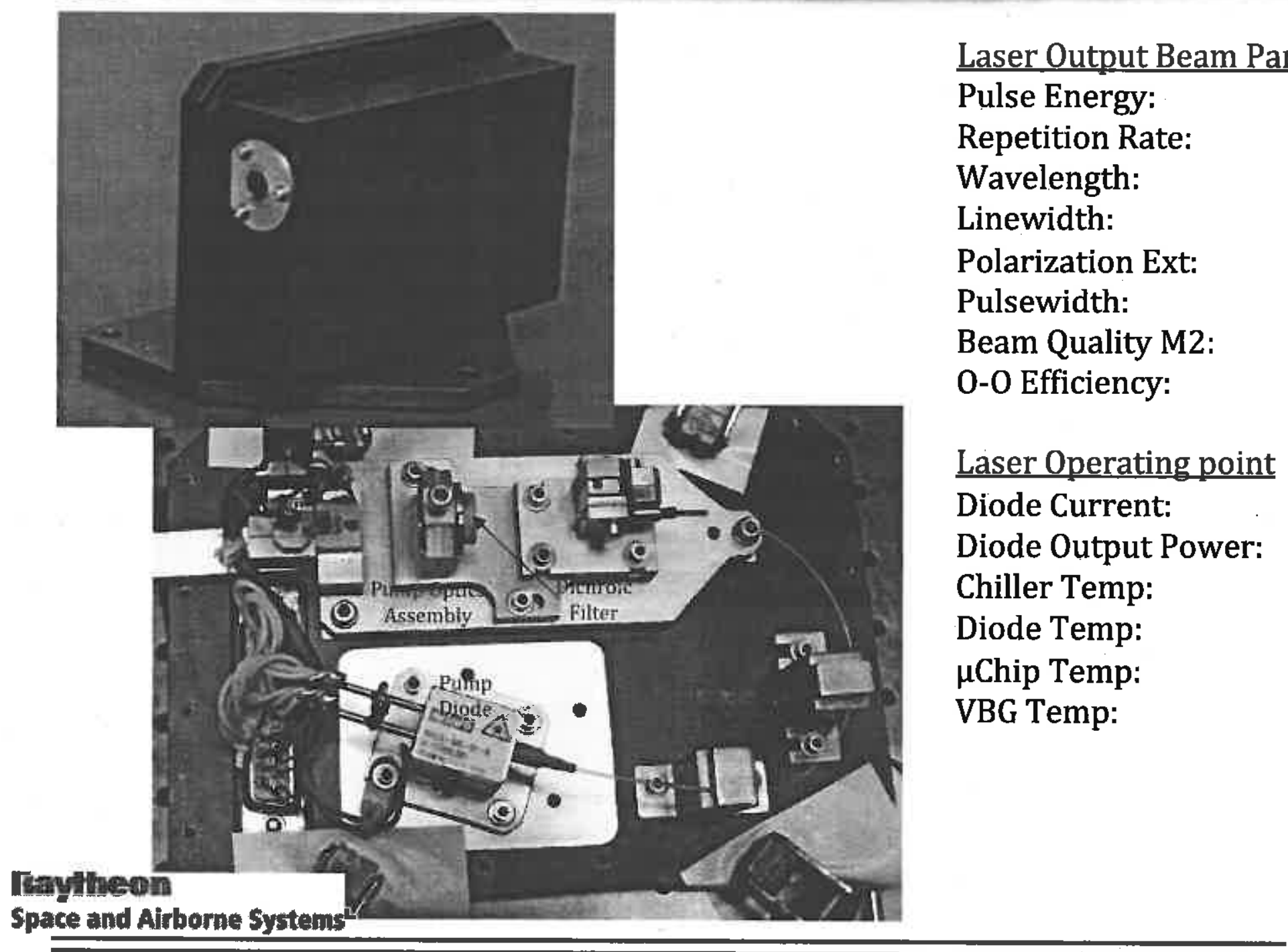

Photonics West 2013 Paper 8599-25

$0.1 \mathrm{~mJ}$

$10 \mathrm{kHz}$

$1030.2 \mathrm{~nm}$

$17 \mathrm{pm}$

$25 \mathrm{~dB}$

$0.83 \mathrm{nsec}$

1.3

$25 \%$

$4.5 \mathrm{~A}$

$3.9 \mathrm{~W}$ $29.8^{\circ} \mathrm{C}$ $31^{\circ} \mathrm{C}$ $17.8^{\circ} \mathrm{C}$ $20^{\circ} \mathrm{C}$

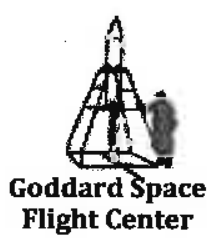




\section{NA SA Packaged MOPA for Swath Mapper IIP - Power Scaling Demonstration}
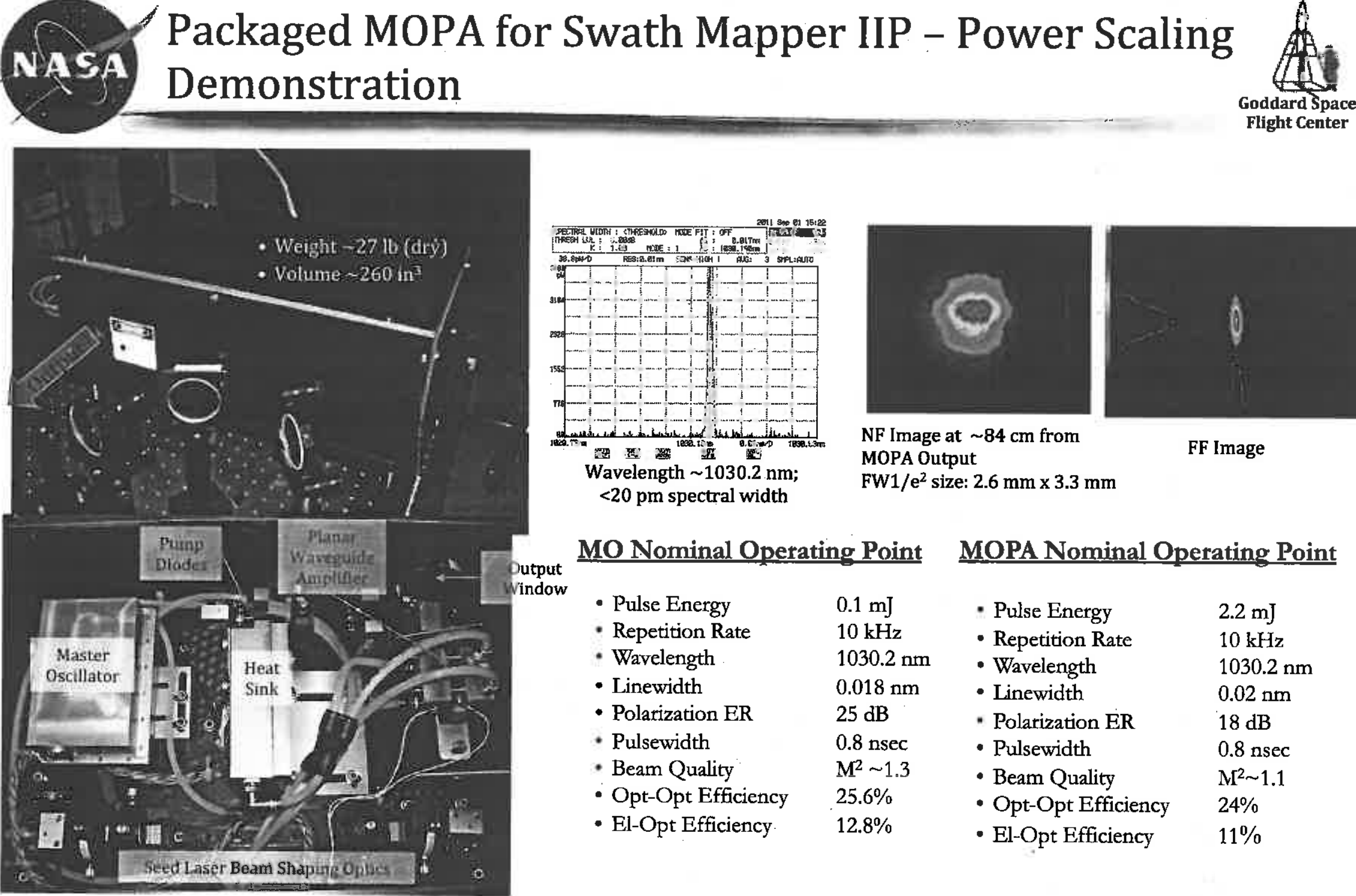

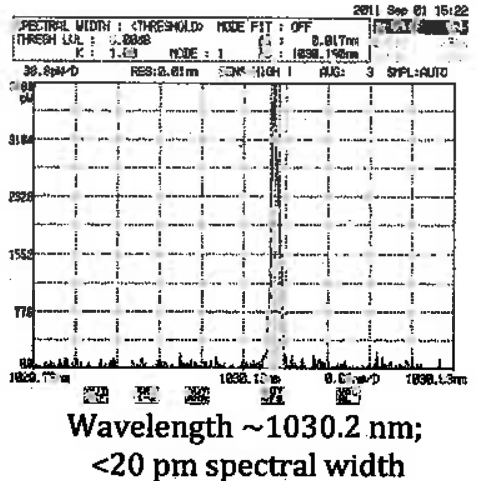

MO Nominal Operating Point

- Pulse Energy

- Repetition Rate

- Wavelength

- Linewidth

- Polarization ER

- Pulsewidth

- Beam Quality

- Opt-Opt Efficiency

- El-Opt Efficiency

$10 \mathrm{kHz}$

$1030.2 \mathrm{~nm}$

$0.018 \mathrm{~nm}$

$25 \mathrm{~dB}$

$0.8 \mathrm{nsec}$

$M^{2} \sim 1.3$

$25.6 \%$

$12.8 \%$

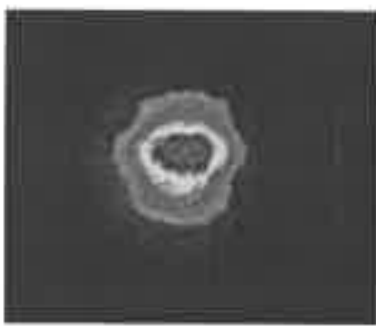

NF Image at $\sim 84 \mathrm{~cm}$ from MOPA Output

FW1/e $\mathrm{e}^{2}$ size: $2.6 \mathrm{~mm} \times 3.3 \mathrm{~mm}$

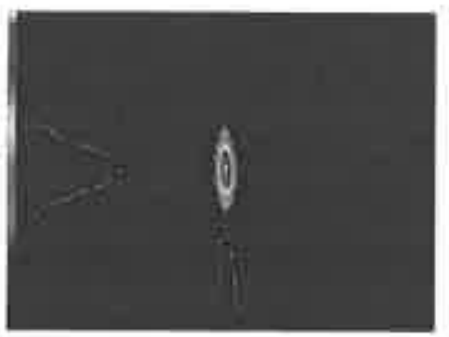

FF Image

MOPA Nominal Operating Point

Pulse Energy

- Repetition Rate

$2.2 \mathrm{~mJ}$

Wavelength

- Linewidth

$10 \mathrm{kHz}$

$1030.2 \mathrm{~nm}$

- Polarization ER

- Pulsewidth

$0.02 \mathrm{~nm}$

$18 \mathrm{~dB}$

$0.8 \mathrm{nsec}$

$\mathrm{M}^{2} \sim 1.1$

- Opt-Opt Efficiency $\quad 24 \%$

- El-Opt Efficiency

\section{ritaytheom}

Space and Alrorne Systems 


\section{NASA Receiver for ALISTS}

Selected the Intevac InGaAsP 4x4 intensified photodiode (IPD)

High performance, large active area ( $\mathrm{mm}$ ), high bandwidth $(\sim 1 \mathrm{GHz})$, high gain $(>10,000)$, high quantum efficiency ( $>20 \%$ )

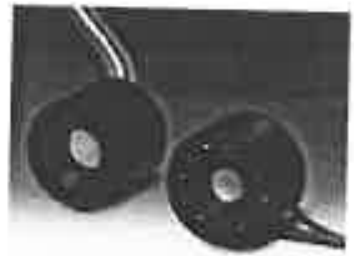

InGaAsP field assisted photocathode with QE up to $25 \%$ over 950-1300 nm

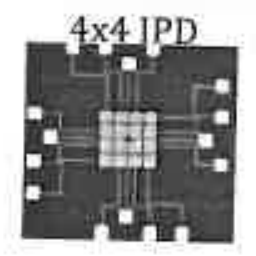

Segmented GaAs APD anodes to form a $4 \times 4$ array

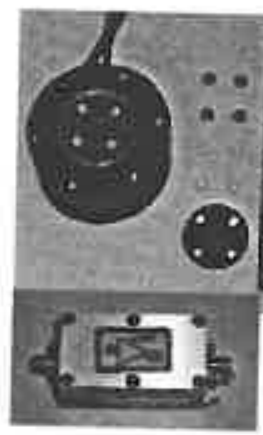

Commercial low noise amplifier
$4 \times 4$ fan-out at the back of the IPD

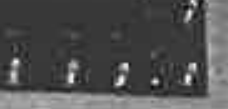

\section{),}

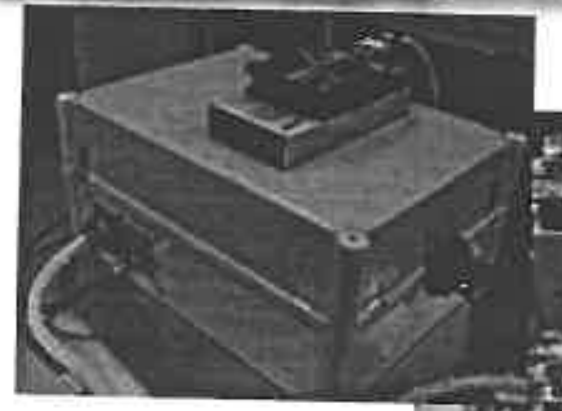

Goddard Space Flight Center

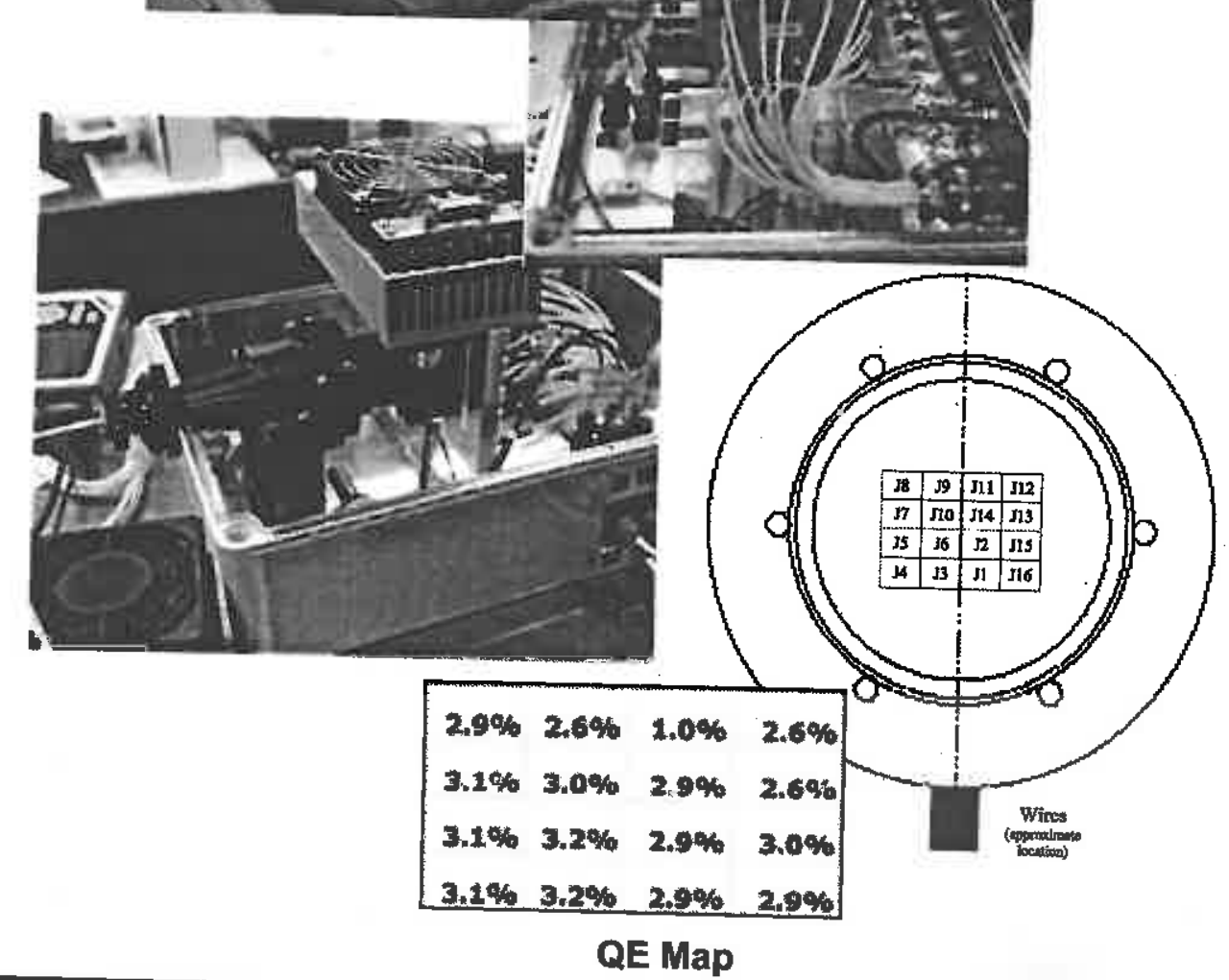

QE Map 


\section{NASA ALISTS on Airborne Platforms}
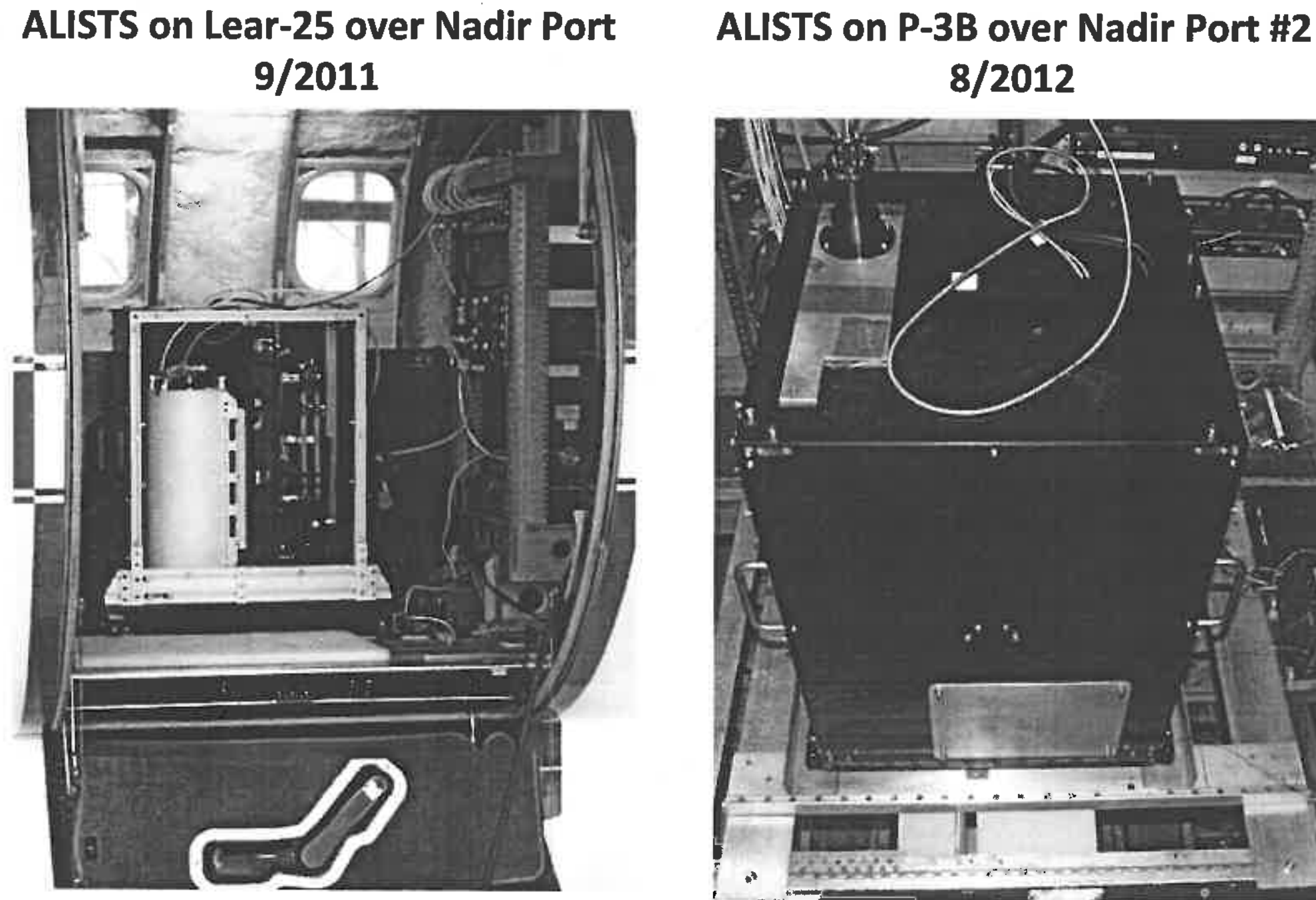

$8 / 2012$

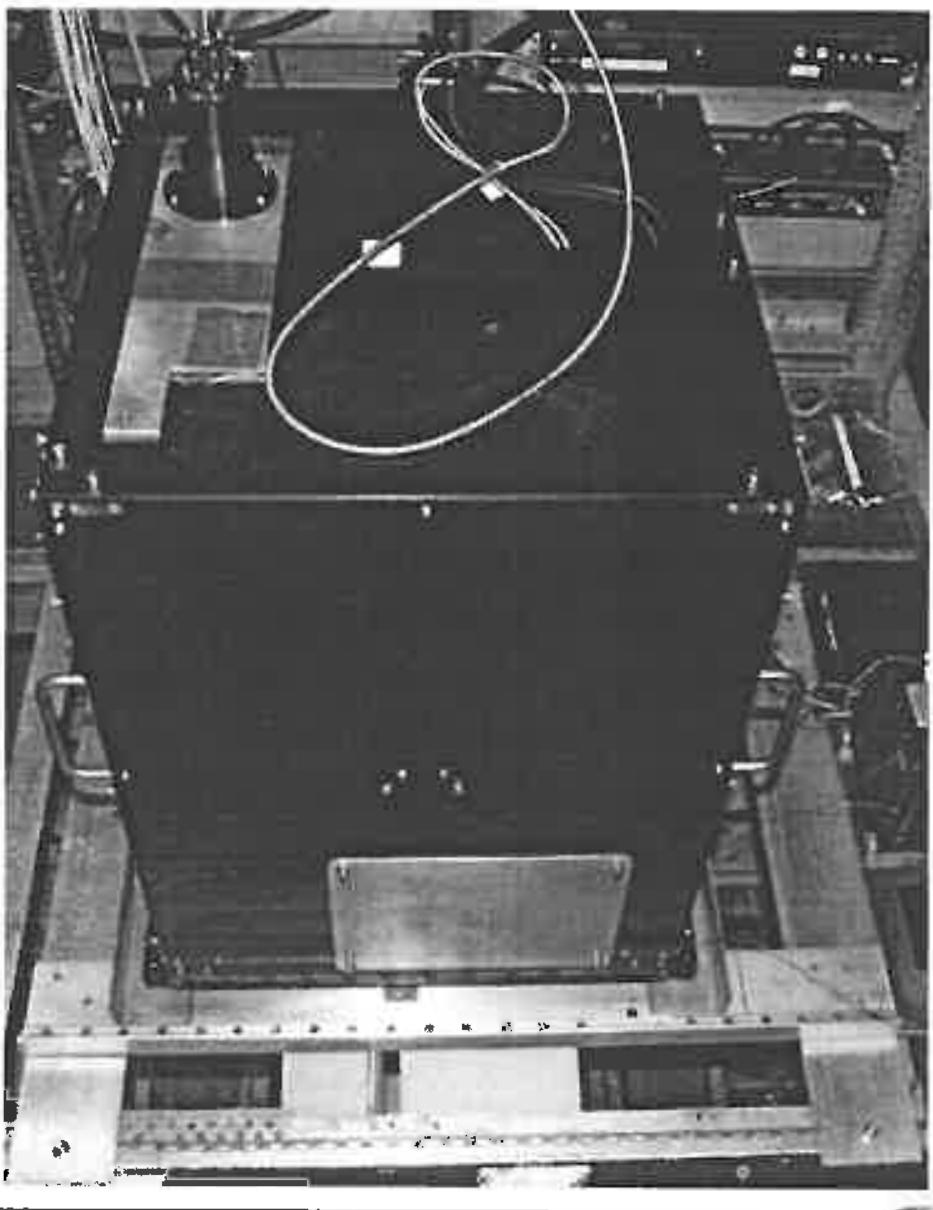




\section{Signal Acquisition Cycle and Data Rates}

- Two acquisition modes for August, 2012 flights:

- Direct (raw): Rx only, 819 meter range gate, $5-\mathrm{kHz}$ rate

- Processed (FPGA): Tx+Rx, 1638-meter range gate, $10-\mathrm{kHz}$ rate

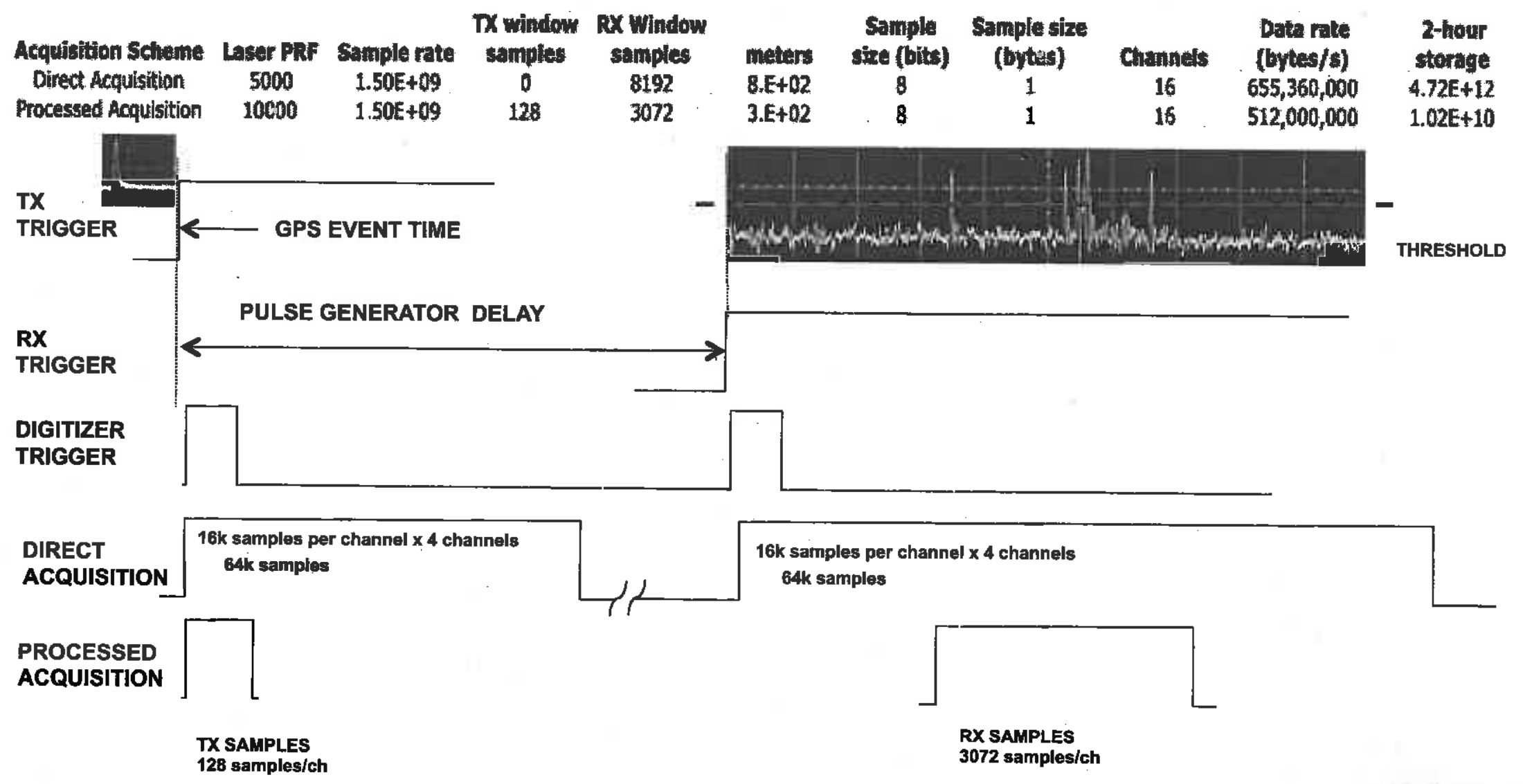




\section{Flight Data Collection, Analysis and Validation}

\section{DAVID HARDING AND SUSAN VALETT}

NASA GSFC CODE 698 \& 587 
- Objectives

- Implement measurement approach using master oscillator laser

- Acquire waveforms over a variety of land cover and terrain types

- Repeat at multiple altitudes up to $10 \mathrm{~km}$ to evaluate link margin model

- Develop data processing, visualization and analysis software

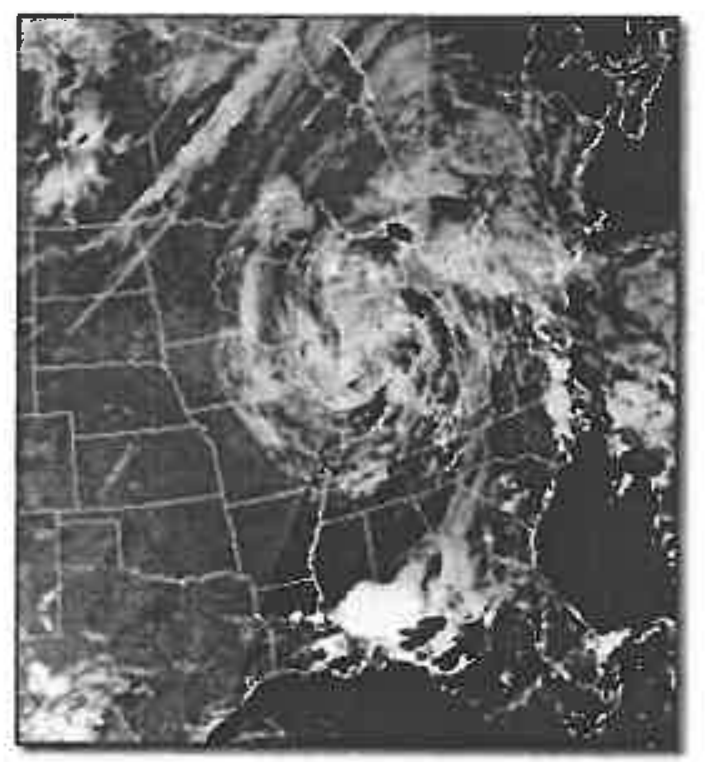

The majority of the objectives were met despite limited data collection opportunities, due to slow-moving east coast "frankenstorm" and laser failure due to over current. 


\section{Land Cover Vertical Structure from ALISTS} Waveforms

- Waveforms acquired from $10 \mathrm{~km}$ altitude

- 200 laser shot average over $20 \mathrm{~m}$ along-track distance

- Vertical structure is consistent with video-documented land cover

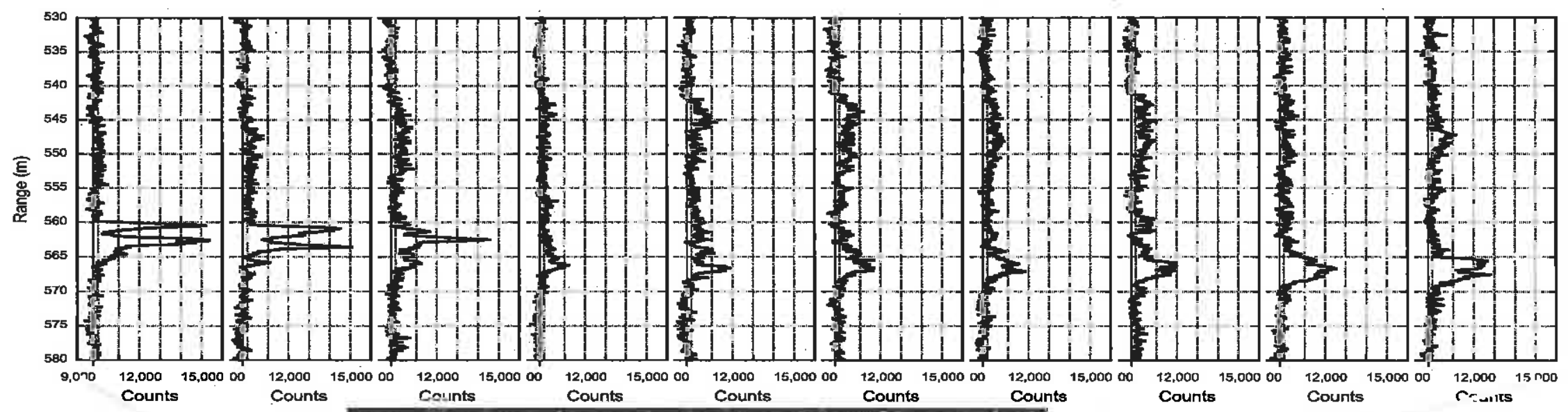

Singie beam

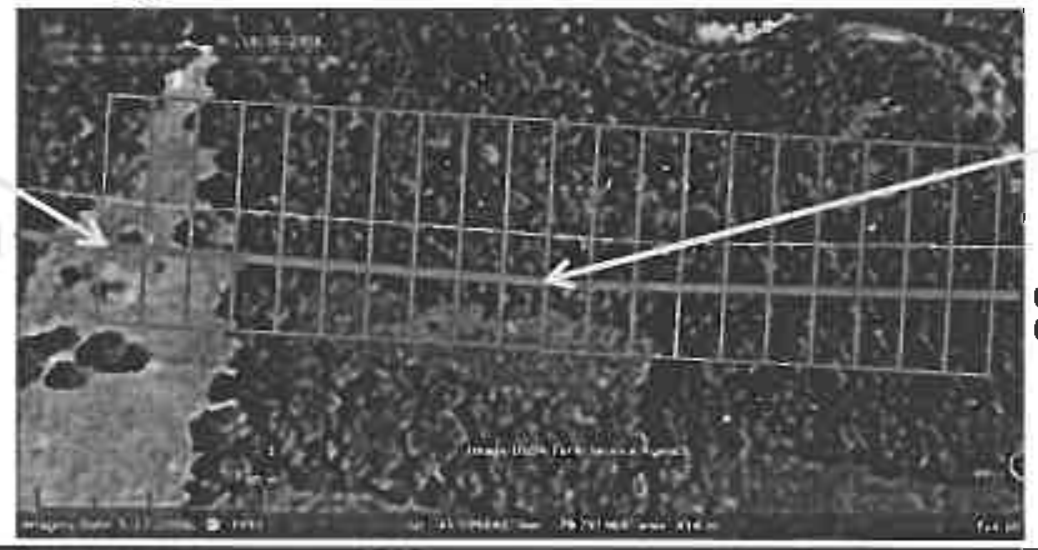

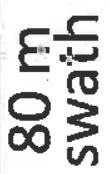




\section{NASA Evaluation of Signal Link Margin Model}

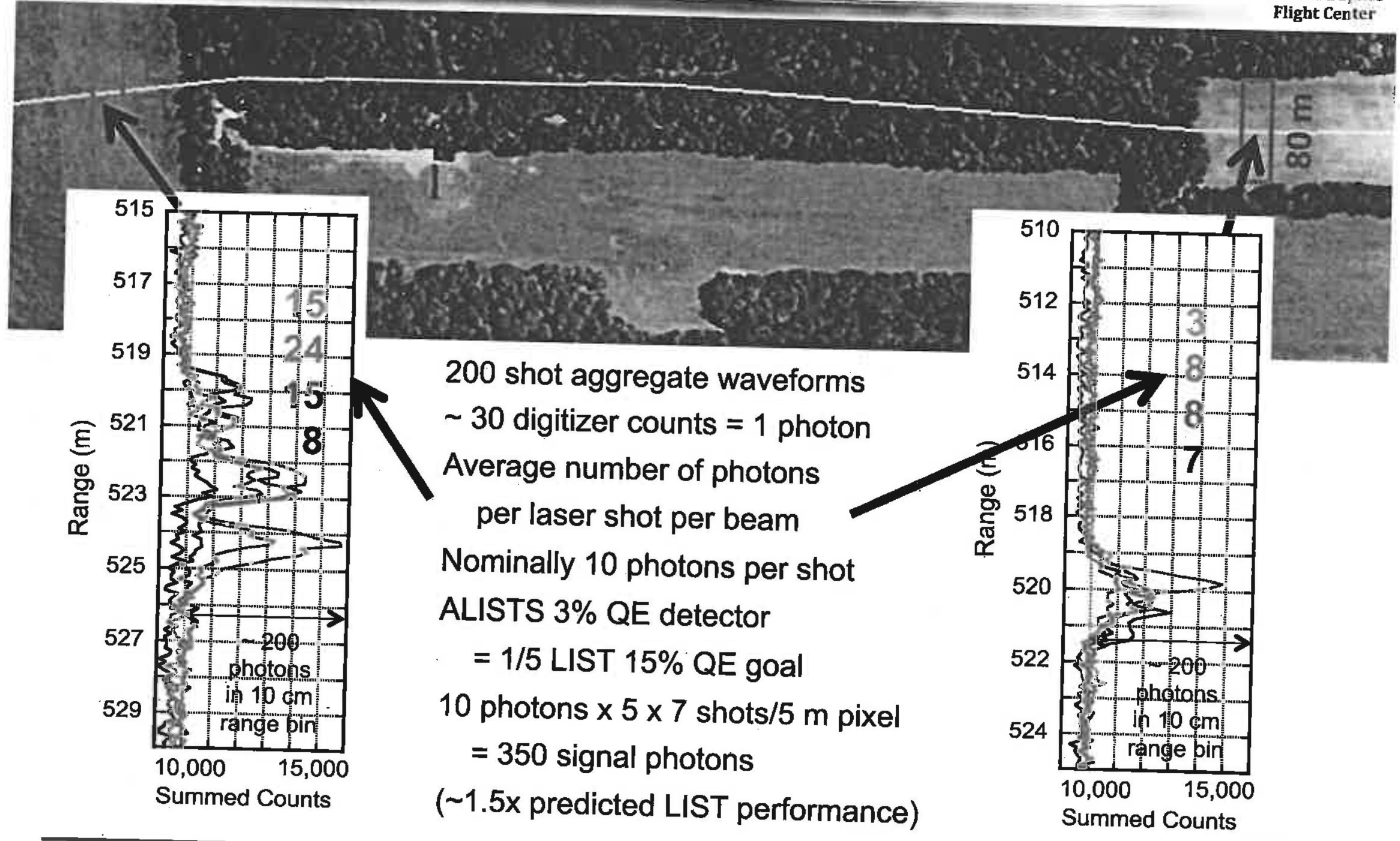




\section{- Objectives}

- Acquire data at $10 \mathrm{~km}$ for several ecosystem research sites

- Validate measurement approach by comparison to independent data

- Utilize master oscillator power amplifier laser in-flight

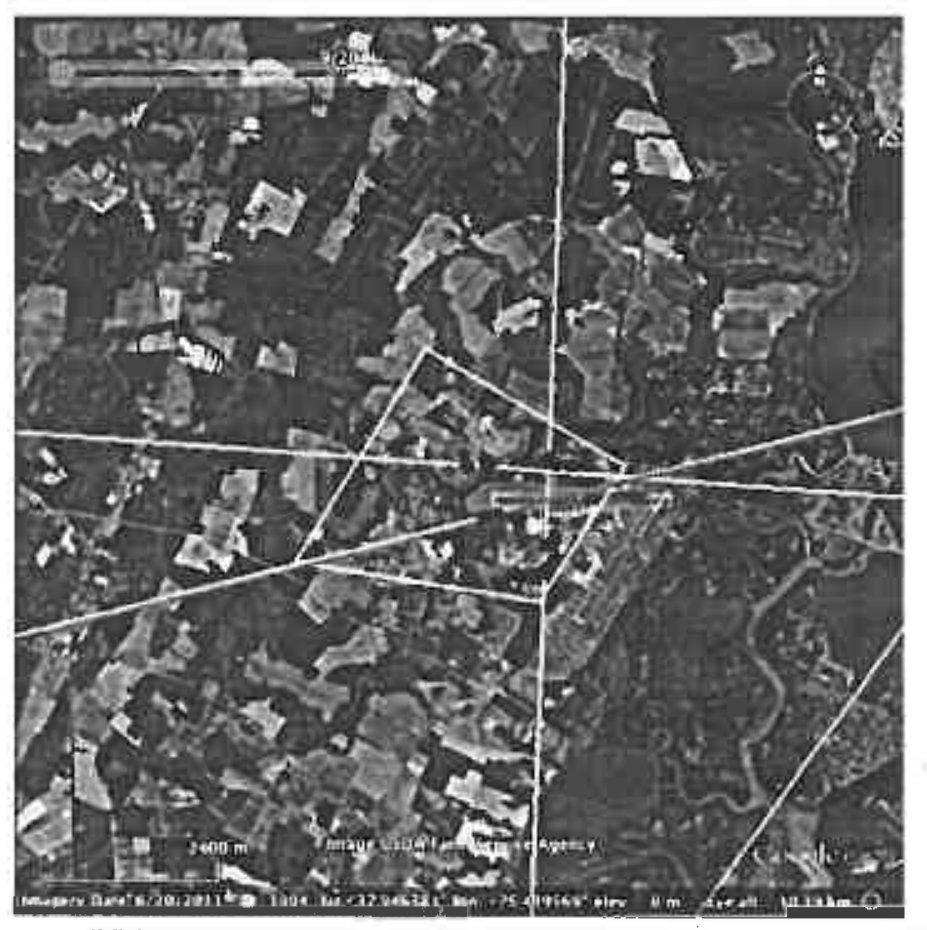

Validation accomplished although flights had to be conducted at $1.5 \mathrm{~km}$ to overcome signal loss due to instrument misalignment and low window transmission and wavefront distortion

ALISTS August, 2012 flight over Wallops Flight Facility Repeated SIMPL August, 20011 lines: yellow Crossed G-LiHT high-res lidar mapping: white outline Targeted field stem map plots: red dots ALISTS and SIMPL comparison: red line 


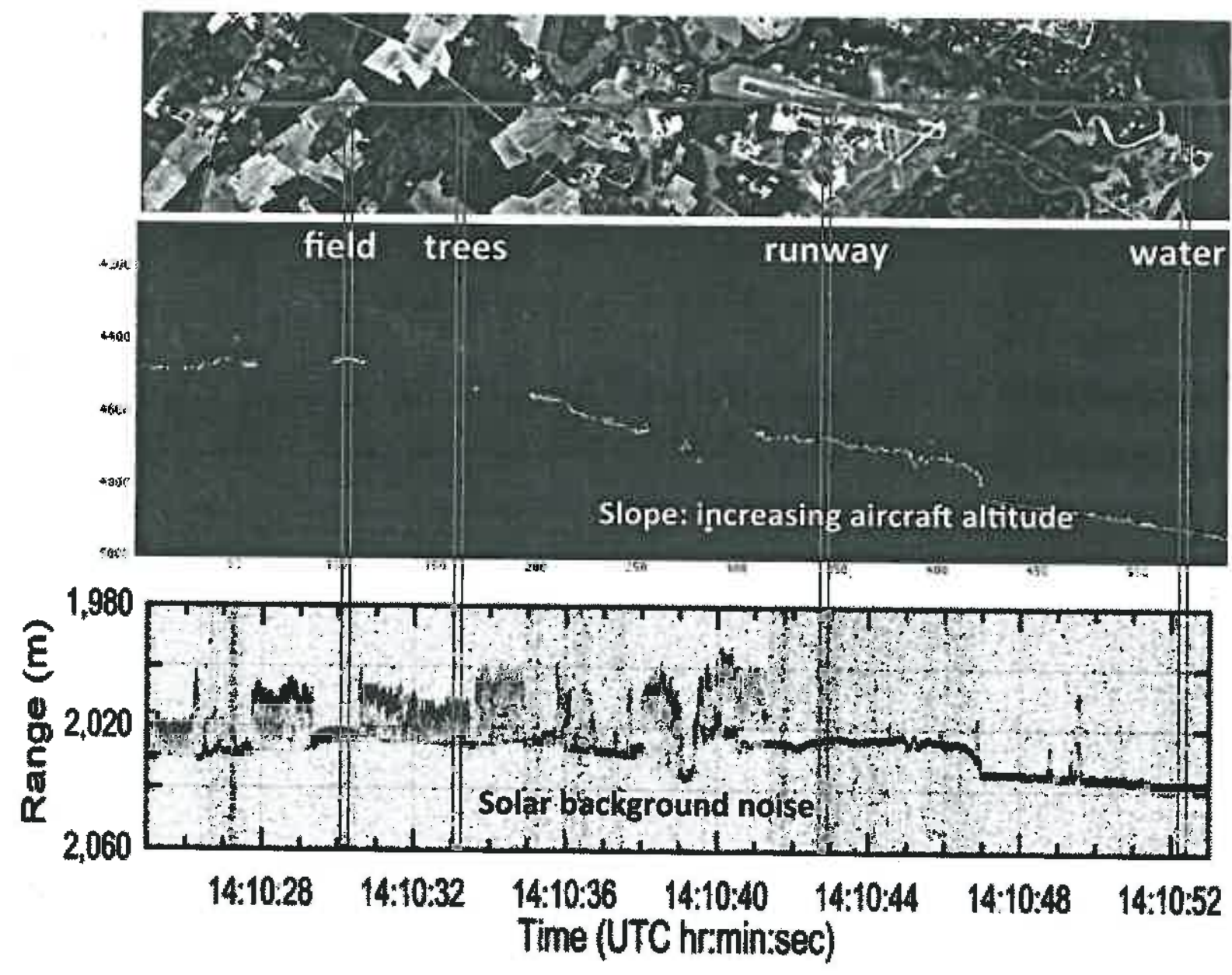

ALISTS 8/29/12

and SIMPL 8/23/11

flight track (red)

ALISTS

Waveforms

1,000 shot averages

Color $=$ amplitude

\section{SIMPL}

Single photons

High sampling density provides validation data 
SIMPL Histogram

One $532 \mathrm{~nm}$ beam of 4

0.2 footprints

Single photon detection

$10 \mathrm{~cm}$ range bins

$\sim 10,000$ laser shots

$\sim 20 \%$ PD

$\sim 100 \mathrm{~m}$ along-track distance

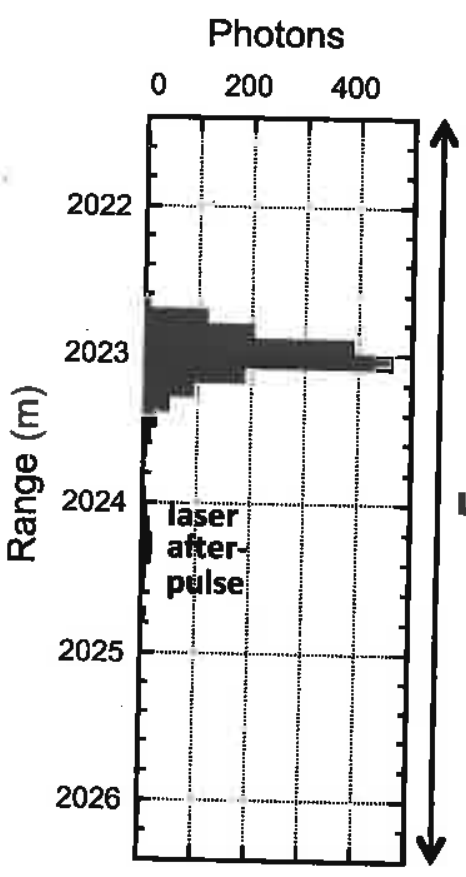

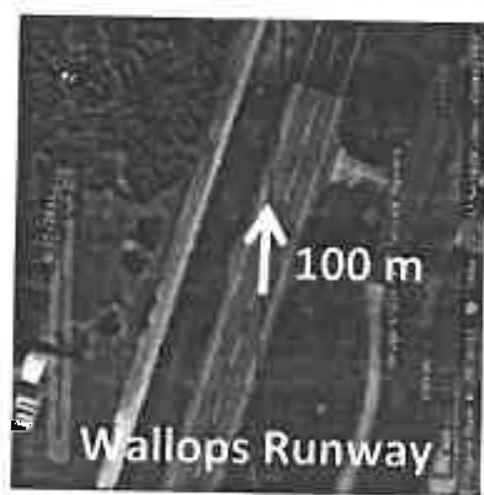

SIMPL \& ALISTS narrow width returns

Similar $\sim 20 \mathrm{~cm}$ FWHM impulse responses

Due to short pulses and high timing resolution

$10 \mathrm{~cm}$ range precision

shown for ALISTS by within-beam range change of $5 \mathrm{~m}$ along-track waveforms across runway
Digitizer Counts Digitizer Counts Digitizer Counts $\begin{array}{lllllllll}9,600 & 10,200 & 10,800 & 0,000 & 10,600 & 11,200 & 9,600 & 10,000 & 10,40\end{array}$

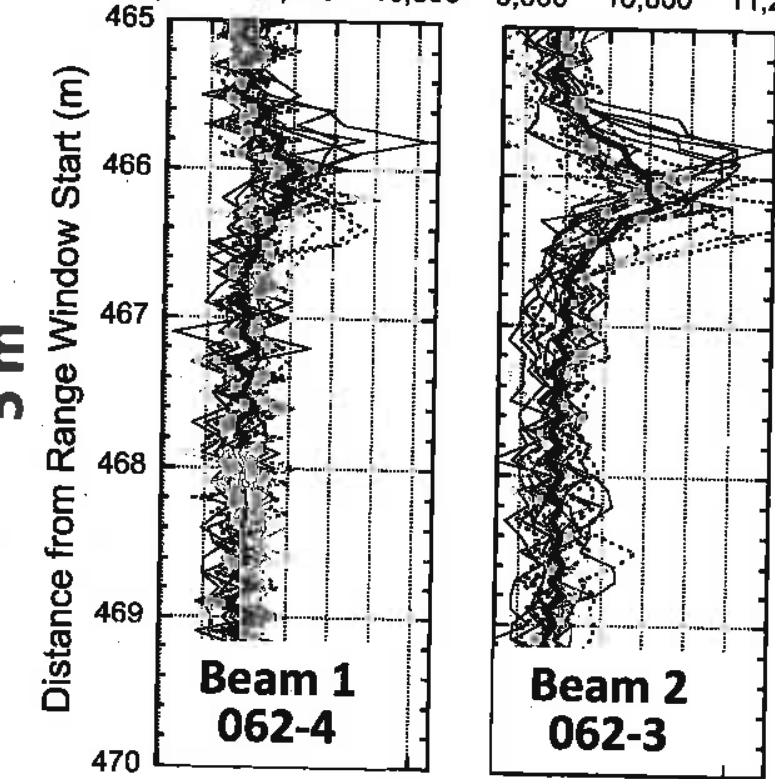

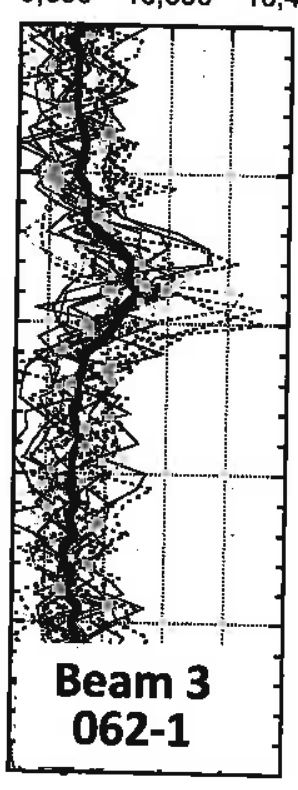

ALISTS Waveforms

Three $1064 \mathrm{~nm}$ beams of 16

$0.7 \mathrm{~m}$ footprints

Linear-mode photon detection

1.5 GHz digitization

$10 \mathrm{~cm}$ range resolution

19 along track waveforms plotted

Each combining 215 laser shots

$\sim 5 \mathrm{~m}$ along-track distance

Average waveform (bold black)

$\sim 100 \mathrm{~m}$ along-track distance

Waveform offsets between beams due to channel timing biases Low SNR due to receiver misalignment and low window

transmission

AWY 03 FEB2012

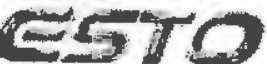




\section{NASA Waveform Validation for Several Surface Types}

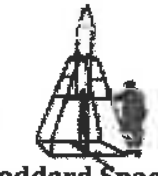

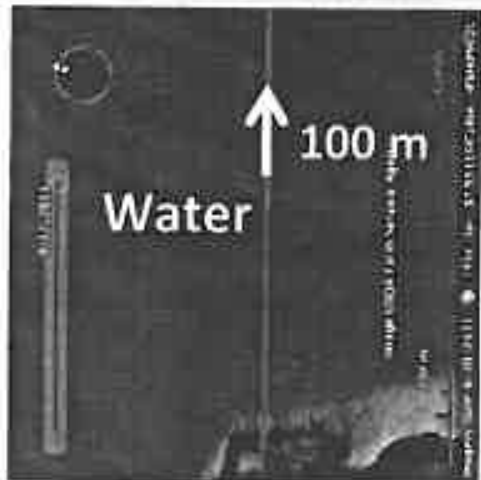

Photons

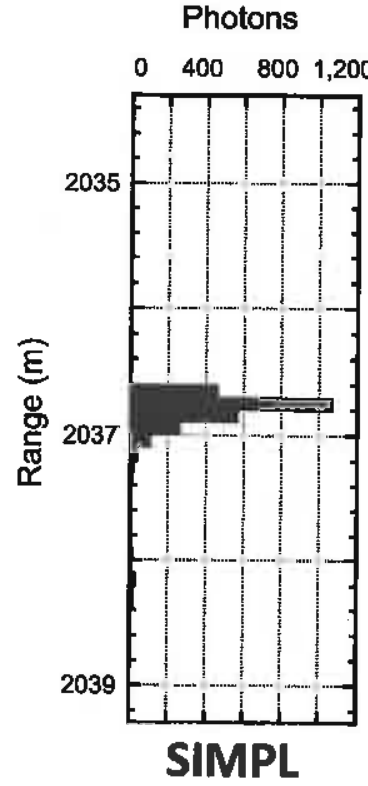

Digitizer Counts
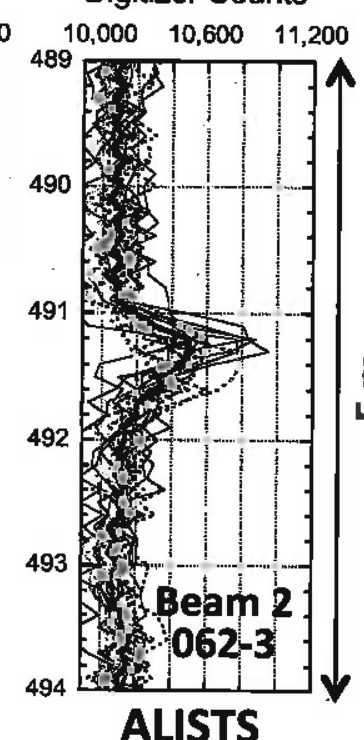

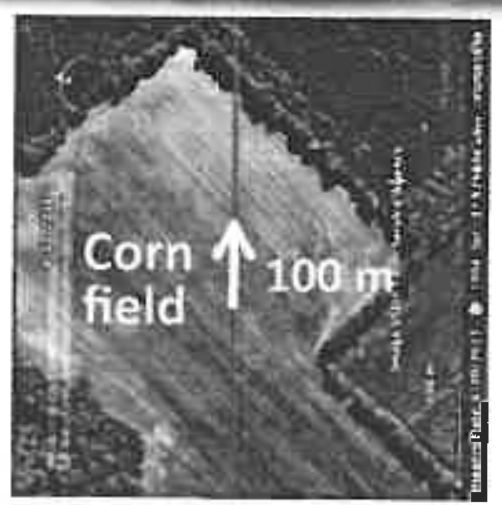

Photons

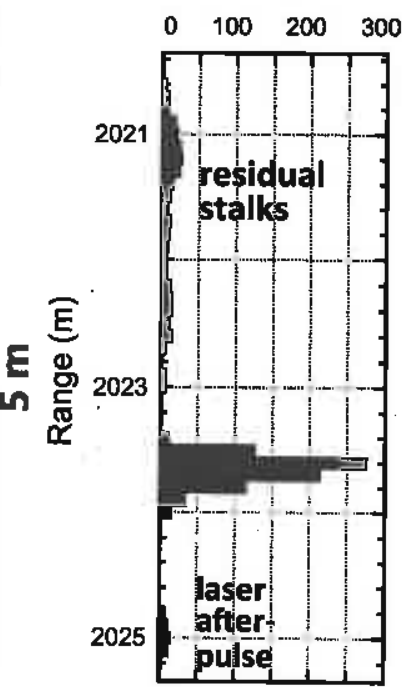

SIMPL
Digitizer Counts
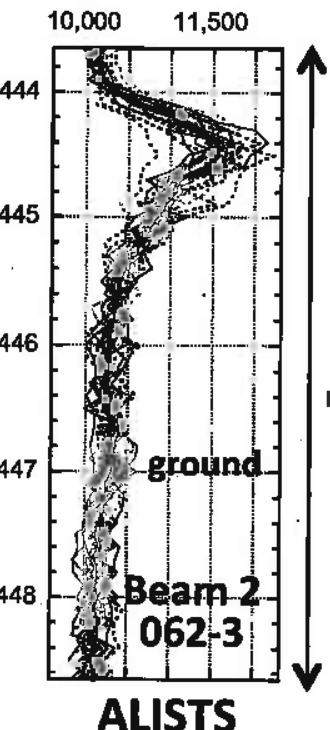

ALISTS

post-harvest pre-harvest

field conditions from in-flight nadir videos

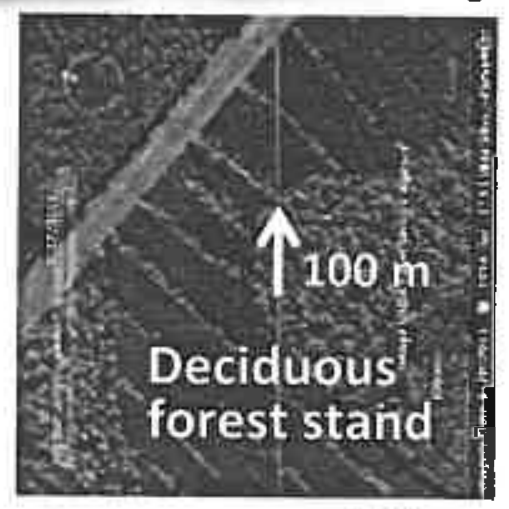

Photons

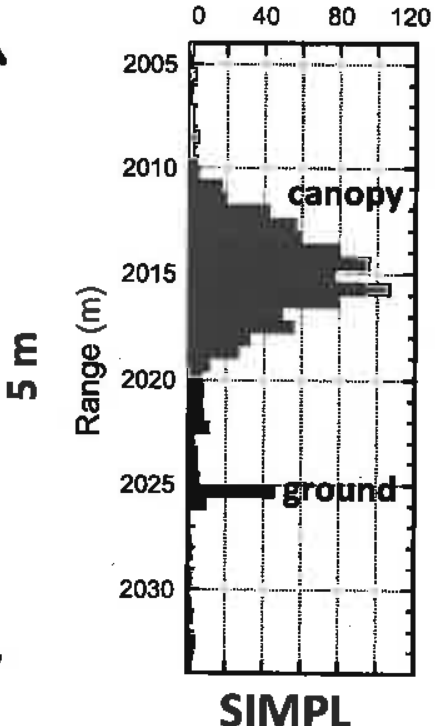

SIMPL
Digitizer Counts

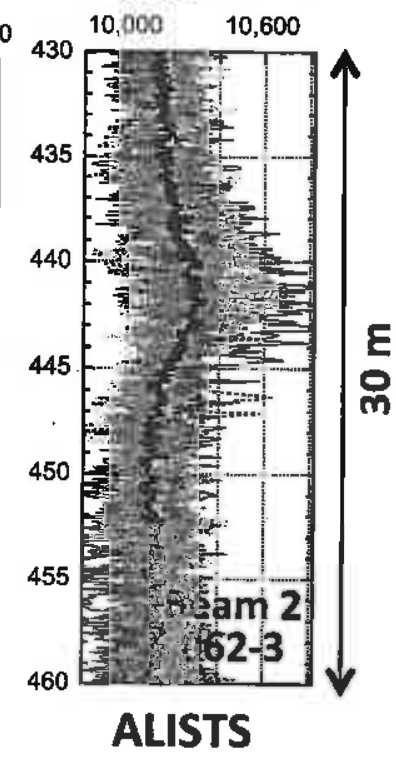


NASA Consistent Waveforms Across the 16 Beam Swath
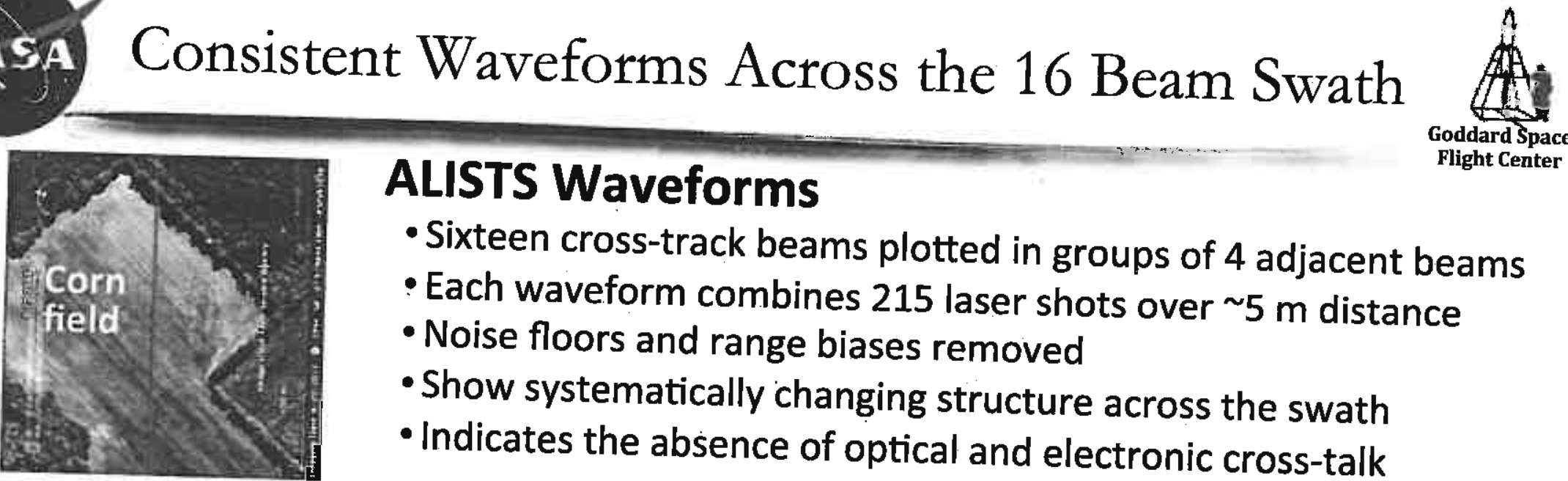

\section{ALISTS Waveforms}

- Sixteen cross-track beams plotted in groups of 4 adjacent beams

- Each waveform combines 215 laser shots over $\sim 5 \mathrm{~m}$ distance

- Noise floors and range biases removed

- Show systematically changing structure across the swath

- Indicates the absence of optical and electronic cross-talk
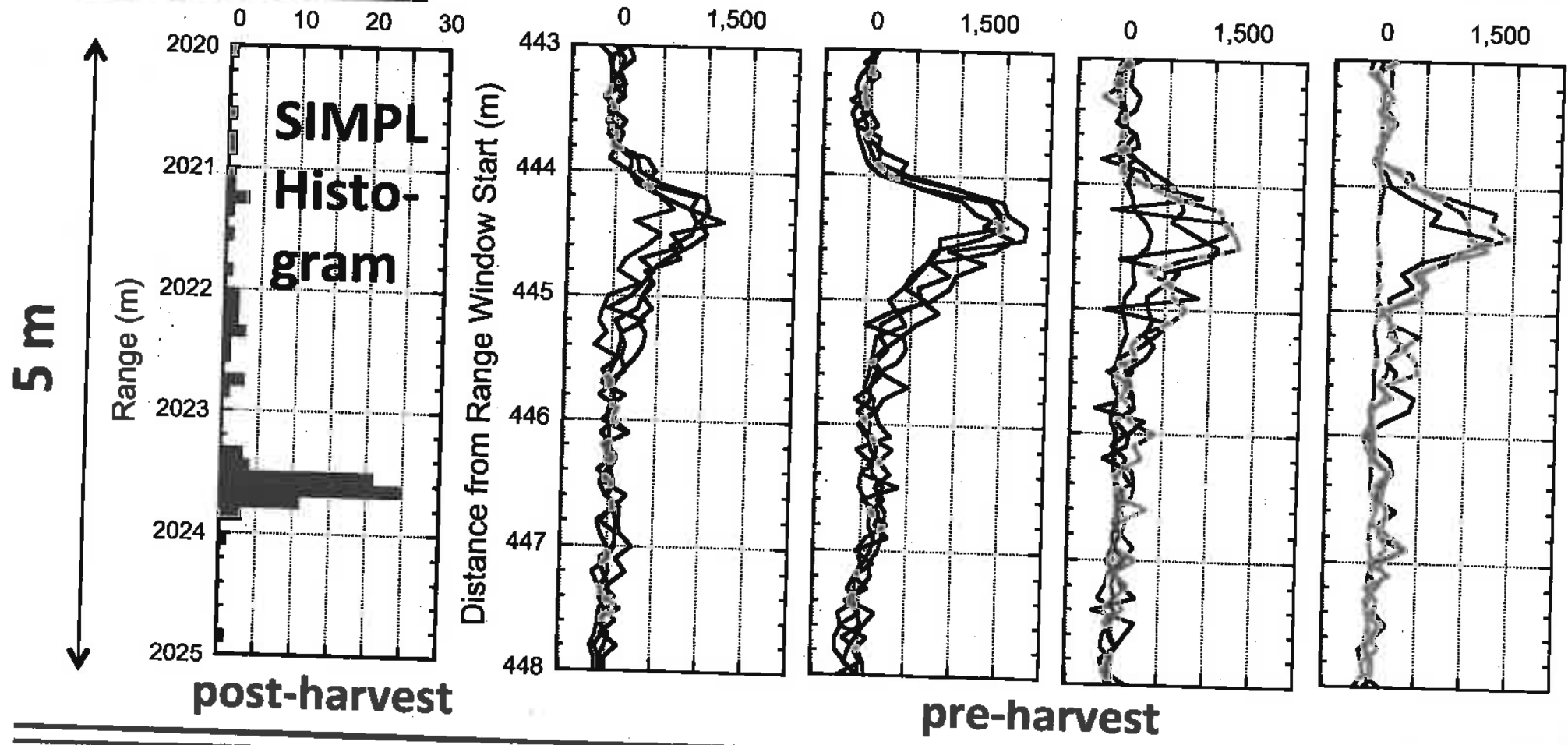

Card

062

112

140

1.95 


\section{Conclusion}

ANTHONY YU AND DAVID HARDING

NASA GSFC CODE 554 AND 698 


\section{IIP Accomplishments}

1. Developed and demonstrated a highly efficient measurement approach that can meet the LIST mission requirements

a. Micropulse, photon-sensitive waveform recording using multi-beam, swath-mapping;

b. Modeled performance to define instrument and sub-system requirements.

2. Working with vendor partners, advanced laser and detector technologies needed to achieve the performance requirements

a. Short pulse $[<1 \mathrm{~ns}$ ) multi-beam laser transmitters with $>12 \%$ wall plug efficiency:

a. Master Oscillator used in airborne flights

b. Master Oscillator Power Amplifier demonstrating power scaling for spaceflight

b. High sensitivity, linear mode array detectors for photon sensitive waveform capturing;

c. Characterized performance of key new components/technologies in the lab and in flight.

3. Designed, assembled, flight tested, and evaluated the Airborne List Simulator, a prototype swath mapping instrument

a. $4 \times 4$ laser array and $4 \times 4$ receiver array for a 16-channel LIST prototype;

b. Same spatial resolution (5-m spot diameters) as LIST;

c. Demonstrated and validated measurements over a variety of surface types, including those of vegetation canopy and underlying topography.

4. Advanced technical readiness of a scalable instrument architecture for LIST

Accomplished goals: Developed and demonstrated a highly efficient measurement approach and worked with vendor partners to mature the needed laser and detector technologies. 


\section{Follow-on Science Plans}

- 3 Year Space Geodesy ROSES-2010 Project

- "Algorithm Development and Observation Strategies for the LIST Geodetic Imaging Mission"

- Acquire ALISTS data for a diverse range of ecology and geomorphology sites

- Develop acquisition algorithms and enhanced science product generation

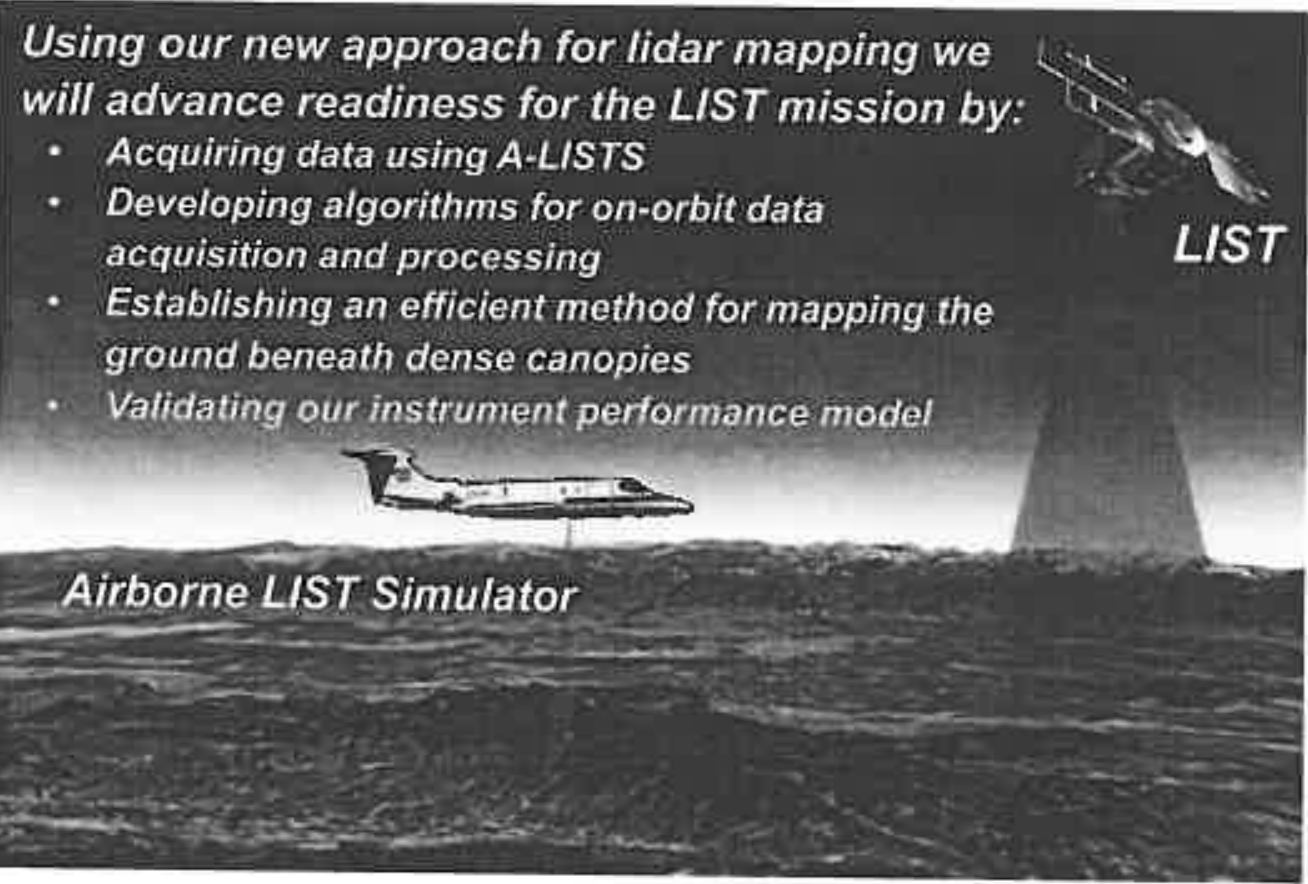


We successfully accomplished the goals of this IIP by: Developing and demonstrating a highly efficient measurement approach that can meet the LIST mission requirements Working with vendor partners, maturing laser and detector technologies needed to achieve the performance requirements Designing, assembling, flight testing, and evaluating the Airborne List Simulator, a prototype swath mapping instrument Advancing the technical readiness of a scalable instrument archilecture forlinST

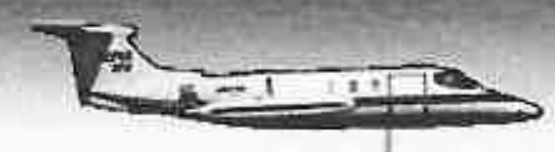

Airborne LIST Simulator

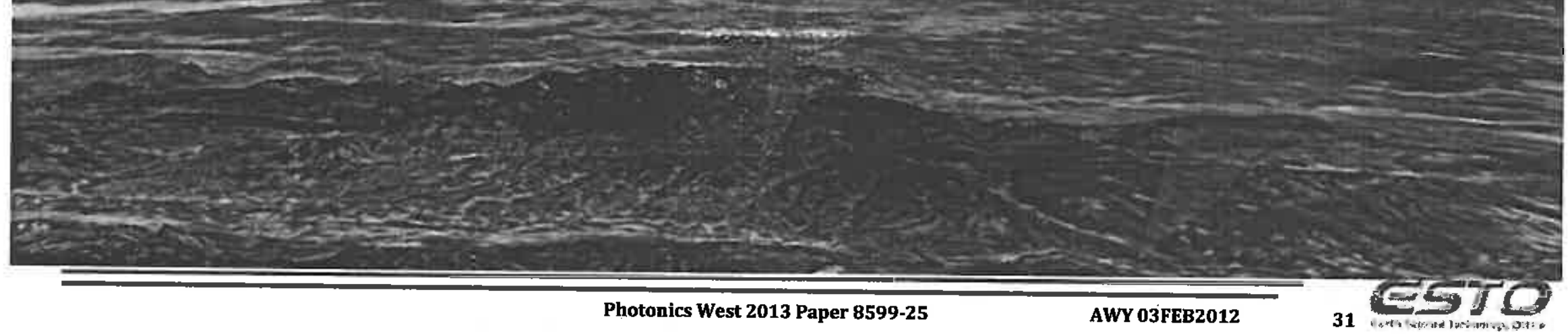

